Artigo

\title{
Distribuições de Tendências Sazonais de Temperatura Média e Precipitação nos Biomas Brasileiros
}

\author{
Júlio César Penereiro ${ }^{1,2}$, Anna Badinger ${ }^{2}$, Nicole Augusto Maccheri ${ }^{2}$, \\ Monica Cristina Meschiatti ${ }^{3}$ \\ ${ }^{1}$ Observatório Municipal de Campinas Jean Nicolini, Campinas, SP, Brasil. \\ ${ }^{2}$ Curso de Graduação em Engenharia Ambiental e Sanitária, \\ Pontifícia Universidade Católica de Campinas, Campinas, SP, Brasil. \\ ${ }^{3}$ Centro de Ecofisiologia e Biofísica, Instituto Agronômico de Campinas, Campinas, SP, Brasil.
}

Recebido em 21 de Abril de 2017 - Aceito em 12 de Julho de 2017

\begin{abstract}
Resumo
O objetivo deste trabalho foi identificar tendências climáticas em séries temporais de precipitação pluviométrica acumulada mensal e de temperatura média do ar mensal, nas quatro estações do ano, registradas em 243 localidades distribuídas pelos biomas do Brasil. Os dados foram extraídos do Instituto Nacional de Meteorologia (INMET). Aplicaram-se os testes estatísticos de Mann-Kendall e de Pettitt. Os resultados estatísticos e os mapas de distribuições de tendências sazonais permitem observar que todos os biomas exibiram ausências de tendências significativas em ambas variáveis meteorológicas. A temperatura média foi a variável em que se mostrou o maior número de tendências positivas ( 72 no outono, 81 no inverno, 80 na primavera e 92 no verão). Tais tendências foram detectadas principalmente durante a década de 1990 e encontram-se nos biomas Amazônia e Cerrado. Tendências negativas foram observadas nos biomas Caatinga e no Cerrado para as estações do outono, inverno e primavera. Para a precipitação, observou-se tendências negativas nas quatro estações do ano, durante as décadas de 1980, 1990 e 2000. Tendências positivas foram observadas na década de 2000 e durante as estações do outono e inverno, especialmente nos biomas Amazônia e Mata Atlântica. Essas tendências podem estar relacionadas aos eventos El Niño e La Niña.
\end{abstract}

Palavras-chave: séries temporais, análises estatísticas, mudanças climáticas.

\section{Distributions of Seasonal Average Temperature and Precipitation Trends in Brazilian Biomes}

\begin{abstract}
The aim of this work was to identify climate trends in seasonal time series for precipitation and average air temperature, observed in 243 municipalities distributed over the Brazilian biomes. The data were obtained from National Institute of Meteorology (INMET). The Mann-Kendall and Pettitt tests were applied. The statistical results and the seasonal trend distributions maps allow us to observe that all biomes exhibit non-significant trends in the both meteorological variables. The average temperature was the variable that showed the highest number of positive trends ( 72 in autumn, 81 in winter, 80 in spring and 92 in summer). Such trends were mostly detected during the decade of 1990 and in the Amazônia and Cerrado biomes. Negative trends were observed in the Caatinga and Cerrado biomes for the seasons of autumn, winter and spring. For the precipitation, negative trends we observed in all the four seasons, during the decades of 1980,1990 and 2000. Positive trends were observed in the decade of 2000 and during the autumn and winter seasons, especially in the Amazônia and Mata Atlântica biomes. These trends seem to be related to the El Niño and La Niña events.
\end{abstract}

Keywords: time series; statistical analysis; climate changes.

Autor de correspondência: Júlio César Penereiro, jcpenereiro@yahoo.com.br. 


\section{Introdução}

Considerando os trabalhos relacionados ao tema alterações climáticas, os relatórios publicados pelo Painel Intergovernamental sobre Mudanças Climáticas (Intergovernmental Panel on Climate Change - IPCC) ocupam posição de destaque no meio científico. De acordo com o Quinto Relatório Científico do IPCC, o aquecimento do sistema climático é inequívoco e desde a década de 1950 muitas alterações observadas são sem precedentes ao longo de décadas e milênios (IPCC, 2013). A atmosfera e o oceano têm aquecido, a quantidade de neve e gelo tem diminuído, o nível do oceano aumentado e a concentração de gases causadores do efeito estufa tem aumentado. A superfície terrestre tem se apresentado sucessivamente mais quente ao longo das três últimas décadas. Foram observados incrementos de até $2,5^{\circ} \mathrm{C}$ no período de 1901 a 2012 no sul da América do Sul, norte da África, região central do continente asiático e norte da América do Norte. Adicionalmente, aumentos na precipitação anual de até $50 \mathrm{~mm}$. ano ${ }^{-1}$.década ${ }^{-1}$ foram observados no sul da América do Sul, norte da Austrália, Europa e sul da América do Norte. Tendências negativas nessa variável também foram observadas na África, sul do continente asiático e sul europeu, com diminuição de 5 a $50 \mathrm{~mm} \cdot$ ano $^{-1}$.década ${ }^{-1}$ (IPCC, 2013). Neste sentido, evidencia-se que estudar as variabilidades climáticas ocorridas no passado possibilita compreender melhor as variabilidades inferidas no presente, além de subsidiar melhores averiguações no comportamento do clima futuro realizados por modelos que levam em consideração diferentes aspectos socioeconômicos, como uso da terra, concentrações de gases de efeito estufa, propagação de alguns tipos de doenças, entre outros (PBMC, 2015).

Algumas incertezas na modelagem do clima ainda existem, pois, conforme Marengo (2006), uma fonte importante adicional de incerteza é em relação à variabilidade natural do clima. Parte desta variabilidade é consequência de perturbações internas do sistema climático que não são forçadas pelos gases de efeito estufa, mas, presume-se que a outra parte das variabilidades climáticas identificadas é consequência do atual aquecimento global observado (Toledo, 2013; IPCC, 2013), além das interferências promovidas pelo ser humano no ambiente, tais como: a crescente urbanização sem planejamento adequado do uso do solo (Zhenmei et al., 2008), degradações de florestas e dos recursos hídricos no que tange aos aspectos quantitativos e qualitativos, em particular na região Norte do Brasil (Groppo et al., 2005; ANA, 2013), dentre outras.

No Brasil, a deficiência de uma rede observacional coerentemente distribuída, a falta de observações meteorológicas de longo prazo, além de eventuais interrupções nas medições observadas, são fatores limitantes para se estudar a variabilidade climática com precisão. Longas séries meteorológicas permitem a verificação da presença de periodicidades, tendências ou descontinuidades climáticas (Blain, 2009). A realização desses estudos envolvendo as séries temporais de variáveis climáticas ocorre por meio de métodos estatísticos paramétricos e não paramétricos, em particular esses últimos, pois eles possuem um embasamento matemático mais rigoroso para os modelos teóricos de descrição climática (Sansigolo e Kayano, 2010).

Um método frequentemente empregado para o estudo de alterações nos padrões climáticos é a verificação de tendência. A tendência, de acordo com Blain (2010), é caracterizada por uma elevação ou diminuição nos valores médios de uma série temporal contendo medições realizadas por equipamentos disponíveis em estações meteorológicas concebidas para essas finalidades. Não obstante, como afirma Blain (2010), a tendência não é, necessariamente, restrita à tendência linear de um parâmetro climático em função do tempo, mas deve conter apenas um máximo ou mínimo no ponto final da série temporal.

Diante do exposto, o objetivo desse estudo é realizar análises de tendências dos regimes sazonais de séries temporais de precipitação pluviométrica e de temperatura média do ar, empregando os dados observados em cidades espalhadas pelos principais biomas do Brasil. As tendências climáticas foram analisadas por meio de mapas das distribuições espaciais. Para tanto, realizaram-se análises das variabilidades de cada série temporal e identificaram-se, por meio de testes estatísticos, os locais e datas das tendências significativas.

\section{Material e Métodos}

\section{1. Área de estudo}

O Brasil possui uma área de aproximadamente $8.515 .767,0 \mathrm{~km}^{2}$, estando localizado entre as longitudes $-73^{\circ} 59^{\prime}$ e $-34^{\circ} 47^{\prime}$ e latitudes $+05^{\circ} 16^{\prime}$ e $-33^{\circ} 45^{\prime}$. Possui 5.569 municípios, além do Distrito Federal, que estão espalhados nos seis principais biomas, a saber: Amazônia, Caatinga, Cerrado, Mata Atlântica, Pantanal e Pampa (IBGE, 2010). Desses, o de maior extensão é o bioma Amazônia, com $4.196 .943 \mathrm{~km}^{2}$, o que equivale a $49,3 \%$ do território brasileiro, seguido do Cerrado, com $2.036 .448 \mathrm{~km}^{2}$ (23,9\%), da Mata Atlântica, com 1.110.182 km² (13,0\%), da Caatinga, com $844.453 \mathrm{~km}^{2}$ (9,9\%), do Pampa, com $176.496 \mathrm{~km}^{2}(2,1 \%)$ e do Pantanal, com $150.355 \mathrm{~km}^{2}$ $(1,8 \%)$ do território nacional (MMA, 2017).

Foram utilizados dados diários de temperaturas média do ar (T-méd.) e precipitação pluvial (Prec.) de 243 localidades, sendo que 25 são capitais de estados (Fig. 1), distribuídas pelos biomas brasileiros. Os dados foram obtidos por meio do Banco de Dados Meteorológicos para Ensino e Pesquisa (BDMEP) do Instituto Nacional de Meteorologia (INMET), compreendendo o período de 1961 a 2015 (INMET, 2016). A Tabela 1 mostra cada estação medidora do INMET tratada neste estudo, incluindo o respectivo bioma e o período utilizado das séries temporais de T-méd. e Prec. 


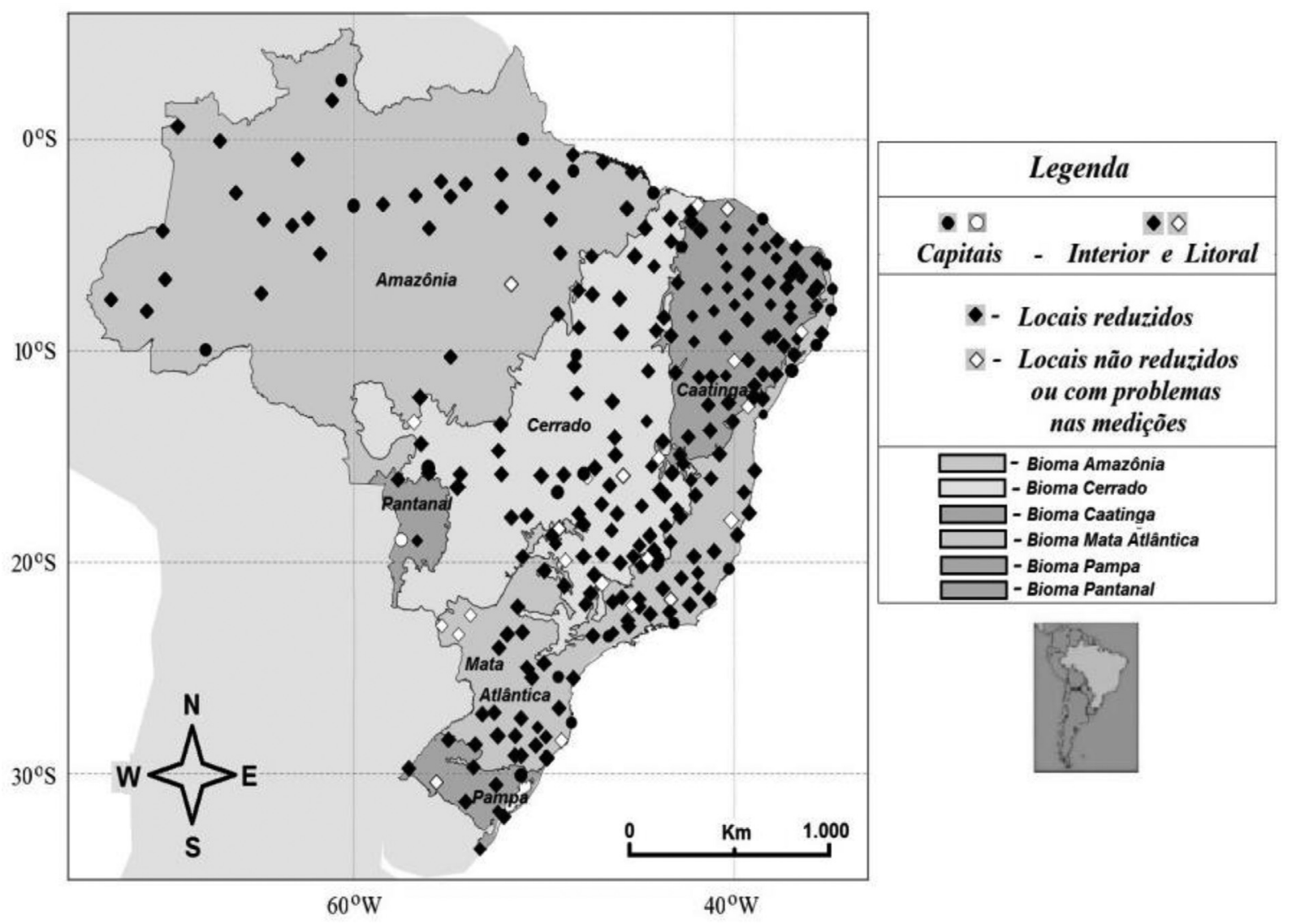

Figura 1 - Distribuição geográfica das estações medidoras pertencentes ao INMET nos biomas do Brasil.

Até a presente data, no endereço eletrônico do INMET, existem dados observados de 266 estações meteorológicas convencionais distribuídas pelo país (INMET, 2016). Ressalta-se que as capitais Campo Grande (MS) e Porto Velho (RO) não possuem estações meteorológicas e, em alguns biomas do Brasil, não existem estações meteorológicas instaladas até o presente momento (Fig. 1), como ocorre particularmente no norte, sul e leste do bioma Amazônia, sul e oeste do Cerrado, além de boa parte do Pantanal.

O levantamento aqui realizado e mostrado corresponde a $91,35 \%$ do total de estações do INMET (Fig. 1), sendo que $70(28,81 \%)$ encontram-se no Cerrado, $64(26,34 \%)$ na Mata Atlântica, $54(22,22 \%)$ na Caatinga, $41(16,87 \%)$ na Amazônia, 11 (4,53\%) no Pampa e apenas 3 (1,23\%) no Pantanal. Essas diferenças se justificam devido às dimensões, às quantidades de ocupações urbanas e às características geográficas intrínsecas de cada bioma brasileiro (INMET, 2016; MMA, 2017).

O banco de dados do INMET não disponibiliza a T-méd. Assim, calculou-se esta variável como a média aritmética diária entre as temperaturas mínima (T-mín.) e máxima (T-máx.), obtendo-se a T-méd. diária. As séries submetidas à análise de tendência são a média mensal da $T$-méd., calculada por meio da média aritmética da T-méd. diária para cada mês para cada estação do ano, e o total mensal de Prec., calculado por meio da soma da Prec. diária para cada mês para cada estação do ano, sendo: MAM (março, abril e maio) para o outono, JJA (junho, julho e agosto) para o inverno, SON (setembro, outubro e novembro) para a primavera e DJF (dezembro, janeiro e fevereiro) para o verão.

O período estudado de cada série depende dos dados disponíveis de uma determinada estação medidora (Tabela 1). Certamente, o ideal seria ter todas as séries temporais em um mesmo período e com mais de 30 anos de observações. Porém, para algumas estações meteorológicas foram identificadas falhas nos dados das séries temporais que, segundo Pickering et al. (1994), podem ter acontecido devido à quebra do equipamento ou ausência do responsável pela medição, erros na calibração de instrumentos, medidas eliminadas por conta de equívoco na leitura, além da mudança de localização das estações ou na exposição dos aparelhos.

É importante salientar as questões envolvidas na qualidade dos dados meteorológicos, que pode comprometer seriamente os resultados de muitas pesquisas baseadas em pressupostos corretos e elaborados com grande sofisticação matemática. São comuns problemas como descontinuidade espacial e temporal dos dados, má distribuição das estações 
Tabela 1 - Estações medidoras do INMET abordadas no presente estudo.

\begin{tabular}{|c|c|c|c|c|c|}
\hline Estação (Estado) & Bioma* & Período & Estação (Estado) & Bioma* & Período \\
\hline Água Branca (AL) & 2 & $1986-2015$ & Correntina (BA) & 3 & $1993-2015$ \\
\hline Aimorés (MG) & 4 & $1986-2015$ & Crateús (CE) & 2 & $1995-2015$ \\
\hline Alagoinhas (BA) & 2 & $1986-2015$ & Cruz Alta (RS) & 5 & $1991-2015$ \\
\hline Altamira (PA) & 1 & $1961-2015$ & Cruzeiro do Sul (AC) & 1 & $1970-2015$ \\
\hline Alto Parnaíba (MA) & 3 & $1977-2015$ & Cruzeta (RN) & 2 & $1969-2015$ \\
\hline Apodi (RN) & 2 & $1996-2015$ & Cuiabá (MT) & 3 & $1961-2015$ \\
\hline Aracajú (SE) & 4 & $1991-2015$ & Curitiba (PR) & 4 & $1961-2015$ \\
\hline Araçuaí (MG) & 4 & $1984-2015$ & Curvelo (MG) & 3 & $1961-2015$ \\
\hline Aragarças (GO) & 3 & $1971-2015$ & Diamantina (MG) & 4 & $1986-2015$ \\
\hline Araguaína (TO) & 1 & $1984-2015$ & Diamantino (MT) & 3 & $1969-2015$ \\
\hline Arcoverde (PE) & 2 & $1972-2015$ & Divinópolis (MG) & 3 & $1996-2015$ \\
\hline Areia (PB) & 2 & $1994-2015$ & Eirunepé (AM) & 1 & 1993-2015 \\
\hline Avelar (RJ) & 4 & $1986-2015$ & Encruzilhada do Sul (RS) & 5 & $1961-2015$ \\
\hline Bacabal (MA) & 3 & $1976-2015$ & Esperantina (PI) & 2 & $1992-2015$ \\
\hline Balsas (MA) & 3 & $1977-2015$ & Espinosa (MG) & 3 & $1974-2012$ \\
\hline Bambuí (MG) & 3 & $1986-2015$ & Feira de Santana (BA) & 4 & $1998-2015$ \\
\hline Barbacena (MG) & 4 & $1961-2015$ & Florânia (RN) & 2 & $1994-2015$ \\
\hline Barbalha (CE) & 3 & $1994-2015$ & Florestal (MG) & 1 & $1990-2013$ \\
\hline Barcelos (AM) & 1 & $1961-2015$ & Floriano (PI) & 3 & $1992-2015$ \\
\hline Bagé (RS) & 5 & $1961-2015$ & Florianópolis (SC) & 4 & $1992-2015$ \\
\hline Barra (BA) & 2 & $1986-2015$ & Fonte Boa (AM) & 1 & $1990-2015$ \\
\hline Barra do Corda (MA) & 3 & $1983-2015$ & Formosa (GO) & 3 & $1974-2012$ \\
\hline Barreiras (BA) & 3 & $1995-2015$ & Fortaleza (CE) & 2 & 1994-2015 \\
\hline Belém (PA) & 1 & $1961-2015$ & Franca (SP) & 3 & $1961-2015$ \\
\hline Belo Horizonte (MG) & 3 & $1961-2015$ & Gleba Celeste (MT) & 1 & $1970-2015$ \\
\hline Belterra (PA) & 1 & $1972-2015$ & Goiânia (GO) & 3 & $1961-2015$ \\
\hline Benjamin Constant (AM) & 1 & $1961-2015$ & Goiás (GO) & 3 & $1961-2015$ \\
\hline Bento Gonçalves (RS) & 5 & $1961-2015$ & Guaramiranga (CE) & 2 & 1994-2015 \\
\hline Boa Vista (RR) & 1 & $1993-2015$ & Guaratinga (BA) & 4 & 1986-2015 \\
\hline Bom Despacho (MG) & 3 & $1981-2015$ & Guarulhos (SP) & 4 & 1984-2015 \\
\hline Bom Jesus (RS) & 4 & $1991-2015$ & Iauretê (AM) & 1 & $1970-2015$ \\
\hline Bom Jesus da Lapa (BA) & 2 & $1986-2015$ & Ibirité (MG) & 4 & $1961-2015$ \\
\hline Bom Jesus do Piauí (PI) & 3 & $1971-2015$ & Iguatu (CE) & 2 & 1995-2015 \\
\hline Brasília (DF) & 3 & $1961-2015$ & Imperatriz (MA) & 3 & $1976-2015$ \\
\hline Breves (PA) & 1 & $1995-2015$ & Indaial (SC) & 4 & $1992-2015$ \\
\hline C. do Mato Dentro (MG) & 3 & $1984-2015$ & Ipameri (GO) & 3 & $1978-2015$ \\
\hline Cabrobó (PE) & 2 & $1992-2015$ & Iraí (RS) & 4 & $1991-2015$ \\
\hline Cárceres (MT) & 6 & $1996-2015$ & Irati (PR) & 4 & $1994-2015$ \\
\hline Caetité (BA) & 2 & $1986-2015$ & Irecê (BA) & 2 & $1996-2015$ \\
\hline Caldeirão (PI) & 2 & $1992-2015$ & Itabaianinha (SE) & 4 & $1995-2011$ \\
\hline Cametá (PA) & 1 & $1970-2015$ & Itaberaba (BA) & 2 & $1995-2015$ \\
\hline Campina Grande (PB) & 2 & $1994-2015$ & Itacoatiara (AM) & 1 & $1971-2015$ \\
\hline Campo Mourão (PR) & 4 & $1961-2015$ & Itaituba (PA) & 1 & $1966-2015$ \\
\hline Campos (RJ) & 4 & $1992-2015$ & Itamarandiba (MG) & 4 & $1990-2015$ \\
\hline Campos do Jordão (SP) & 4 & $1961-2015$ & Itaperuna (RJ) & 4 & $1990-2015$ \\
\hline Campos Novos (SC) & 4 & $1969-2015$ & Itiruçu (BA) & 4 & $1993-2015$ \\
\hline
\end{tabular}


Tabela 1 (cont.)

\begin{tabular}{|c|c|c|c|c|c|}
\hline Estação (Estado) & Bioma* & Período & Estação (Estado) & Bioma* & Período \\
\hline Campos Sales (CE) & 2 & 1994-2012 & Ituaçu (BA) & 2 & $1998-2015$ \\
\hline Canarana (MT) & 1 & 1996-2015 & Ituiutaba (MG) & 3 & $1984-2015$ \\
\hline Canavieiras (BA) & 4 & 1993-2015 & Itumbiara (GO) & 3 & $1994-2015$ \\
\hline Caparaó (MG) & 4 & 1991-2015 & Ivaí (PR) & 4 & $1977-2015$ \\
\hline Capinópolis (MG) & 3 & 1990-2015 & Jacobina (BA) & 2 & $1995-2015$ \\
\hline Caracaraí (RR) & 1 & $1978-2015$ & Jaguaruana (CE) & 2 & $1994-2015$ \\
\hline Caracol (PI) & 3 & 1992-2015 & Janaúba (MG) & 2 & $1992-2015$ \\
\hline Caratinga (MG) & 4 & $1986-2015$ & Januária (MG) & 3 & $1976-2015$ \\
\hline Caravelas (BA) & 4 & 1993-2012 & Jataí (GO) & 3 & $1978-2015$ \\
\hline Carbonita (MG) & 3 & 1981-2015 & João Pessoa (PB) & 4 & $1986-2015$ \\
\hline Carinhanha (BA) & 3 & 1990-2015 & João Pinheiro (MG) & 3 & $1961-2015$ \\
\hline Carolina (MA) & 3 & 1969-2015 & Juiz de Fora (MG) & 4 & $1961-2015$ \\
\hline Castro (PR) & 4 & $1996-2015$ & Juramento (MG) & 3 & $1988-2015$ \\
\hline Catalão (GO) & 3 & 1961-2015 & Lábrea (AM) & 1 & $1993-2015$ \\
\hline Catanduva (SP) & 4 & 1961-2015 & Lages (SC) & 4 & $1991-2015$ \\
\hline Caxias (MA) & 3 & $1961-2015$ & Lagoa Vermelha (RS) & 4 & $1998-2015$ \\
\hline Caxias do Sul (RS) & 4 & 1991-2015 & Lavras (MG) & 4 & $1961-2015$ \\
\hline Ceará Mirim (RN) & 3 & 1994-2015 & Lençóis (BA) & 2 & $1995-2015$ \\
\hline Chapadinha (MA) & 3 & $1978-2015$ & Londrina (PR) & 4 & $1961-2015$ \\
\hline Chapecó (SC) & 4 & $1992-2015$ & Luzilândia (PI) & 3 & $1994-2015$ \\
\hline Cipó (BA) & 2 & 1986-2015 & Macapá (AM) & 1 & $1968-2015$ \\
\hline Coari (AM) & 1 & $1970-2015$ & Macau (RN) & 2 & $1995-2015$ \\
\hline Codajás (AM) & 1 & 1993-2015 & Maceió (AL) & 4 & $1993-2015$ \\
\hline Colinas (AM) & 3 & 1976-2015 & Machado (MG) & 4 & $1991-2015$ \\
\hline Conceição do Araguaia (PA) & 1 & 1961-2015 & Manaus (AM) & 1 & $1961-2015$ \\
\hline Cordeiro (RJ) & 4 & 1996-2011 & Manicoré (AM) & 1 & $1993-2015$ \\
\hline Marabá (PA) & 1 & $1973-2015$ & Remanso (BA) & 2 & $1986-2015$ \\
\hline Maringá (PR) & 4 & $1961-2015$ & Resende (RJ) & 4 & $1961-2015$ \\
\hline Matupá (MT) & 1 & $1998-2015$ & Rio Branco (AC) & 1 & $1970-2015$ \\
\hline Monte Alegre (PA) & 1 & 1975-2015 & Rio de Janeiro (RJ) & 4 & $2002-2015$ \\
\hline Monte Azul (MG) & 3 & 1975-2015 & Rio Grande (RS) & 5 & $1988-2015$ \\
\hline Monte Santo (BA) & 2 & 1995-2015 & Rio Verde (GO) & 3 & $1996-2015$ \\
\hline Monteiro (PB) & 2 & 1995-2015 & Rondonópolis (MT) & 3 & $1995-2015$ \\
\hline Montes Claros (MG) & 3 & $1988-2015$ & Salinas (MG) & 4 & $1975-2015$ \\
\hline Morada Nova (CE) & 2 & $1962-2015$ & Salvador (BA) & 4 & $1986-2015$ \\
\hline Morro do Chapéu (BA) & 2 & 1986-2015 & Santa Maria (RS) & 5 & $1991-2015$ \\
\hline Natal (RN) & 4 & $1984-2015$ & Santa Rita de Cássia (BA) & 3 & $1993-2015$ \\
\hline Nhumirim (MS) & 6 & 1993-2015 & Santa Vitória do Palmar (RS) & 5 & $1961-2015$ \\
\hline Nova Xavantina (MT) & 3 & 1998-2015 & São Carlos (SP) & 3 & $1961-2015$ \\
\hline Óbidos (PA) & 1 & 1970-2015 & São Gabriel da Cachoeira (AM) & 1 & $1961-2015$ \\
\hline Ouricuri (PE) & 2 & 1994-2015 & São Gonçalo (PB) & 2 & $1994-2015$ \\
\hline Padre Ricardo Remetter (MT) & 6 & 1998-2015 & São João do Piauí (PI) & 2 & $1995-2015$ \\
\hline Palmas (TO) & 3 & 1994-2015 & São Joaquim (SC) & 4 & $1961-2015$ \\
\hline Palmeira dos Índios (PE) & 2 & 1994-2015 & São Lourenço (MG) & 4 & $1961-2015$ \\
\hline Pão de Açúcar (AL) & 2 & 1995-2015 & São Luís (MA) & 1 & $1971-2015$ \\
\hline Paracatu (MG) & 3 & 1990-2015 & São Luís Gonzaga (RS) & 5 & $1991-2015$ \\
\hline Paranaguá (PR) & 4 & $1961-2015$ & São Mateus (ES) & 4 & $1992-2015$ \\
\hline
\end{tabular}


Tabela 1 (cont.)

\begin{tabular}{|c|c|c|c|c|c|}
\hline Estação (Estado) & Bioma* & Período & Estação (Estado) & Bioma* & Período \\
\hline Paranaíba (MS) & 3 & $1993-2015$ & São Paulo (SP) & 4 & $1961-2015$ \\
\hline Parintins (AM) & 1 & $1993-2015$ & São Simão (SP) & 3 & $1961-2015$ \\
\hline Passo Fundo (RS) & 4 & $1961-2015$ & Seridó (RN) & 2 & $1995-2015$ \\
\hline Patos (PB) & 2 & $1994-2015$ & Serrinha (BA) & 2 & $1993-2015$ \\
\hline Patos de Minas (MG) & 3 & $1961-2015$ & Sete Lagoas (MG) & 3 & $1993-2015$ \\
\hline Paulistana (PI) & 2 & $1994-2015$ & Sobral (CE) & 2 & $1994-2015$ \\
\hline Paulo Afonso (BA) & 2 & $1986-2015$ & Sorocaba (SP) & 4 & $1978-2015$ \\
\hline Pedra Azul (MG) & 4 & $1984-2015$ & Soure (PA) & 1 & $1961-2015$ \\
\hline Pedro Afonso (TO) & 3 & $1977-2015$ & Surubim (PE) & 2 & $1994-2015$ \\
\hline Peixe (TO) & 3 & $1975-2015$ & Taguatinga (TO) & 3 & $1961-2015$ \\
\hline Pelotas (RS) & 5 & $1991-2015$ & Tarauacá (AC) & 1 & $1993-2015$ \\
\hline Petrolina (PE) & 2 & $1991-2015$ & Tauá (CE) & 2 & $1994-2015$ \\
\hline Picos (PI) & 2 & $1994-2015$ & Taubaté (SP) & 4 & $1992-2015$ \\
\hline Pirapora (MG) & 3 & 1961-2012 & Tefé (AM) & 1 & $1970-2015$ \\
\hline Pirenópolis (GO) & 3 & $1976-2015$ & Teresina (PI) & 3 & $1993-2015$ \\
\hline Piripiri (PI) & 2 & $1994-2015$ & Torres (RS) & 4 & $1991-2015$ \\
\hline Poços de Caldas (MG) & 4 & $1992-2015$ & Tracuateuá (PA) & 1 & $1973-2015$ \\
\hline Pompeu (MG) & 3 & $1972-2015$ & Triunfo (PE) & 2 & 1994-2015 \\
\hline Ponta Porã (MS) & 3 & $2000-2012$ & Tucuruí (PA) & 1 & $1971-2015$ \\
\hline Porto Alegre (RS) & 5 & $1961-2015$ & Turiaçu (MA) & 1 & $1976-2015$ \\
\hline Porto de Moz (PA) & 1 & $1966-2015$ & Unaí (MG) & 3 & $1978-2015$ \\
\hline Porto de Pedras (AL) & 4 & $1986-2015$ & Uruguaiana (RS) & 5 & $1992-2015$ \\
\hline Porto Nacional (TO) & 3 & $1961-2015$ & Vale do Gurgueia (PI) & 3 & $1995-2015$ \\
\hline Posse (GO) & 3 & $1977-2015$ & Viçosa (MG) & 4 & $1990-2015$ \\
\hline Poxoréo (MT) & 3 & $1995-2015$ & Vitória (ES) & 4 & $1991-2015$ \\
\hline Presidente Prudente (SP) & 4 & $1961-2011$ & Vitória da Conquista (BA) & 2 & $1993-2015$ \\
\hline Propriá (SE) & 2 & $1992-2015$ & Votuporanga (SP) & 4 & $1977-2015$ \\
\hline Quixeramobim (CE) & 2 & $1994-2015$ & Zé Doca (MA) & 1 & $1976-2015$ \\
\hline Recife (PE) & 4 & $1961-2015$ & & & \\
\hline
\end{tabular}

(*) Bioma: 1 - Amazônia; 2 - Caatinga; 3 - Cerrado; 4 - Mata Atlântica; 5 - Pampa e 6 - Pantanal.

meteorológicas, dificuldades em se manter equipamentos em áreas perigosas ou inóspitas, mudança dos equipamentos para locais bem diferentes das condições iniciais, além da falta de verba para a instalação ou manutenção dos equipamentos. No intuito de minimizar e preencher possíveis falhas nos dados meteorológicos optou-se pela utilização do cálculo da média com grau três, isto é, calculando a média dos três dias anteriores ou posteriores, se os mesmos também não estivessem com esses erros, conforme Penereiro et al. (2016). Caso as falhas fossem de um período de tempo muito longo, isso é, mais de três dias sem dados, realizou-se uma média entre os três mesmos meses de anos anteriores ou posteriores, conforme cada caso específico.

Nos casos em que as séries mensais apresentavam falhas de três anos ou mais, optou-se por eliminar os dados anteriores a essas falhas, restando séries de períodos menores que as originais, porém de maior consistência de dados para serem tratados estatisticamente. Isso explica o fato de cada localidade apresenta um período de estudo diferenciado, como é possível constatar na Tabela 1.

Os dados foram organizados e tratados em planilhas do software Microsoft Office Excel, o que possibilitou a realização dos cálculos visando inferir a ocorrência de uma eventual tendência e a variabilidade dos parâmetros climáticos de interesse, além da geração de gráficos e a realização de análises estatísticas acuradas.

\subsection{Testes estatísticos utilizados}

De acordo com Naghettini e Pinto (2007), os testes estatísticos podem ser classificados em paramétricos e não paramétricos. Por serem os testes não paramétricos de Mann-Kendall e de Pettitt os que possuem maiores embasamentos matemáticos e estatísticos (Sansigolo e Kayano, 2010), no presente trabalho optou-se por apresentar os 
resultados obtidos na aplicação desses testes, cujas formulações são descritas suscintamente a seguir.

\subsubsection{Teste Mann-Kendall}

O teste sequencial de Mann-Kendall (Sneyers, 1975) é uma análise estatística não paramétrica que considera a hipótese de estabilidade de uma série cuja sucessão de valores ocorre de forma independente, sendo que a distribuição de probabilidade deve permanecer sempre a mesma (série aleatória simples).

Moraes et al. (1995) e Back (2001) descreveram esse método considerando uma série temporal da variável de interesse $Y_{i}$ com $N$ termos, sendo $1 \leq i \leq N$. Realiza-se a soma $t_{n}=\sum_{i=1}^{N} m_{i}$ do número de termos $m_{i}$ da série, relativo ao valor $Y_{i}$ cujos termos precedentes $(j<i)$ são inferiores ao mesmo $\left(Y_{j}<Y_{i}\right)$. Verifica-se que para séries com grande número de termos $(N)$, sob a hipótese nula $\left(H_{0}\right)$ e ausência de tendência, $t_{n}$ apresentará uma distribuição normal com média e variância dada respectivamente pelas Eqs. (1)-(2):

$$
\begin{aligned}
& E\left(t_{n}\right)=\frac{N(N-1)}{4} \\
& \operatorname{Var}\left(t_{n}\right)=\frac{N(N-1)(2 N+5)}{72}
\end{aligned}
$$

Testando a significância estatística de $t_{n}$ para a hipótese nula, usando um teste bilateral, esta pode ser rejeitada para grandes valores da estatística $U\left(t_{n}\right)$, fornecida pela Eq. (3):

$$
U\left(t_{n}\right)=\frac{\left(t_{n}-E\left(t_{n}\right)\right)}{\sqrt{\operatorname{Var}\left(t_{n}\right)}}
$$

Em seguida, através de uma tabela de distribuição normal padronizada, o valor da probabilidade $\alpha_{1}$ é calculado por $\alpha_{1}=\operatorname{prob}\left(|U|>\left|U\left(t_{n}\right)\right|\right)$. Sendo $\alpha_{0}$ o nível de significância do teste, a hipótese nula é aceita se $\alpha_{1}>\alpha_{0}$. Caso a hipótese nula seja rejeitada, implicará a existência de tendência significativa, sendo que o sinal da estatística $U\left(t_{n}\right)$ indica se a tendência é decrescente $\left(U\left(t_{n}\right)<0\right)$ ou então crescente $\left(U\left(t_{n}\right)>0\right)$. Neste caso, em sua versão sequencial, a equação $U\left(t_{n}\right)$ é calculada no sentido direto da série, partindo do valor $i=1$ até $i=N$, gerando a estatística $-1,65<U\left(t_{n}\right)<+1,96$, sendo os valores dos intervalos bilaterais $-1,65 \mathrm{a}+1,65$ e $-1,96 \mathrm{a}+1,96$ correspondentes a $\alpha_{0}=0,10$ (em 10\%) e $\alpha_{0}=0,05$ (em 5\%), respectivamente (Mortatti et al., 2004).

O ponto de início de uma mudança na série pode ser determinado aplicando-se o mesmo princípio à série inversa. De forma análoga, porém no sentido inverso da série temporal original, ao partir do valor $i=N$ até $i=1$, gera-se a estatística inversa $U^{*}\left(t_{n}\right)$. A intersecção das duas curvas estatísticas $U\left(t_{n}\right)$ e $U^{*}\left(t_{n}\right)$, fornece a localização do ponto aproximado de mudança de tendência. Entretanto, isso só é significativo caso este ponto ocorra dentro do intervalo de significância bilateral, isto é, entre -1,65 e +1,96 (Back, 2001).

\subsubsection{Teste Pettitt}

O teste de Pettitt (Pettitt, 1979), também descrito por Moraes et al. (1995) e Back (2001), verifica se duas amostras $Y_{1}, Y_{2}, \ldots, Y_{t}$ e $Y_{t+1}, Y_{t+2}, \ldots, Y_{T}$ são pertencentes à mesma população. Neste caso, a estatística $u_{(t, T)}$ é realizada por meio de uma contagem do número de vezes que um membro da primeira amostra é maior que um membro da segunda amostra, o que pode ser determinado de acordo com a Eq. (4):

$$
u_{(t, T)}=u_{(t-1, T)}+\sum_{j=1}^{T} \operatorname{sgn}\left(Y_{i}-Y_{y}\right) ; t=2, \ldots, T
$$

em que $\operatorname{sgn}\left(Y_{i}-Y_{j}\right)=1$ para $Y_{i}>Y_{j} ; \operatorname{sgn}\left(Y_{i}-Y_{j}\right)=0$ para $Y_{i}=Y_{j}$ e $\operatorname{sgn}\left(Y_{i}-Y_{j}\right)=-1$, para $Y_{i}<Y_{j}$.

A partir desta prerrogativa a estatística $u_{(t, T)}$ é então calculada para valores de $1 \leq t \leq T$. Na sequência, obtém-se a estatística $K(t)$ por intermédio do máximo valor absoluto de $u_{(t, T)}$. É com a estatística de $K(t)$ que se localiza o ponto $t$ em que houve uma mudança brusca na série temporal, sendo que sua significância pode ser avaliada pela Eq. (5):

$$
p \cong 2 e^{\left(\frac{-6 K(t)^{2}}{T^{3}-T^{2}}\right)}
$$

O ponto de mudança brusca é o valor de $t$ onde ocorre o máximo (ou mínimo) de $K(t)$. Com a equação anterior é possível inferir o valor crítico $\left(K_{c r i t}\right)$ do cálculo estatístico usando a Eq. (6):

$$
K_{\text {crit. }}= \pm \sqrt{\frac{-\ln \left(\frac{p}{2}\right)\left(T^{3}+T^{2}\right)}{6}}
$$

Neste teste adotam-se os níveis de significância da mudança em $5 \%$ e $10 \%$ usando o valor de $K_{\text {crit }}$ da série temporal trabalhada (Back, 2001).

\section{Resultados e Discussão}

Optou-se por apresentar alguns resultados em formato gráfico, complementados com tabelas que resumem as informações obtidas de todas as análises estatísticas de cada variável climatológica do levantamento realizado. Esses resultados passam a ser discutidos e analisados para as variáveis climáticas tratadas nesta pesquisa, como consequência da aplicação dos testes estatísticos discutidos anteriormente.

\subsection{Tendências inferidas ou não pelos testes estatísticos}

Formas gráficas dos testes de Mann-Kendall e de Pettitt foram obtidas para T-méd. e Prec. de todas as 243 localidades. A título de exemplificação, selecionaram-se alguns gráficos dos dois testes estatísticos aplicados 
(Figs. 2 e 3). Observa-se, por meio dos gráficos contidos nas Figs. 2 e 3, diferentes comportamentos das curvas estatísticas que determinam a presença ou ausência de tendência climática nas variáveis T-Méd. e Prec.

Nas Figs. 2 e 3 estão apresentados os resultados das análises de T-Méd. da estação MAM de São Gabriel da Cachoeira (bioma Amazônia; Figs. 2a e 2b), T-Méd. da estação SON de Resende (Mata Atlântica; Figs. 2c e 2d), Prec. da estação MAM de Morada Nova (Cerrado; Figs. 3a e 3b) e Prec. da estação DJF de Brasília (Cerrado; Figs. 3c e 3d). Observa-se que foram respeitados os critérios dos intervalos de significância, isto é, para o teste de MannKendall as linhas horizontais pontilhadas e tracejadas indicam os níveis de significâncias de $\pm 5 \%$ a $\pm 10 \%$, com os valores dos intervalos bilaterais $-1,96$ a $+1,96$ e $-1,65$ a $+1,65$, respectivamente. O mesmo ocorreu com o teste de Pettitt, isto é, as linhas horizontais pontilhadas e tracejadas correspondem aos níveis de significância de mudança que foram estimados para $5 \%$ e $10 \%$ do valor calculado de $K_{\text {crit }}$.

Ressalta-se que, no teste de Mann-Kendall, a tendência é significativa quando os valores absolutos de $U\left(t_{n}\right)$ são maiores que os intervalos de confiança e o início dessa tendência podem ser identificados pela intersecção das curvas $U\left(t_{n}\right)$ (em traçado contínuo) e $U^{*}\left(t_{n}\right)$ (em traçado pontilhado), representadas na parte esquerda dos gráficos das figuras a seguir. Porém isso deve ocorrer dentro dos valores críticos dos intervalos de confiança (Groppo et al., 2005).
No caso do teste de Pettitt, que se apresenta na parte direita dos gráficos das Figs. 2 e 3, adotou-se a mesma notação. Porém, neste teste o ponto de mudança brusca da estatística $K(t)$, tomado em módulo, ocorre quando este for maior que os limites críticos estabelecidos de $5 \%$ e $10 \%$. No entanto, essa condição deixa de ser verdadeira quando os valores que estão em seguida ao valor crítico oscilam em intervalos próximos ao valor máximo. Nesta situação, o último valor do intervalo de oscilação indica o ponto de início da tendência (Pettitt, 1979).

Para os dois testes utilizou-se a seguinte convenção: tendência positiva confirmada entre $5 \%$ e $10 \%$ dos níveis dos intervalos de confianças $(+)(+)$; acima de $10 \%$ do nível do intervalo de confiança $(+)$ e, de maneira análoga, (-)(-) e (-) para tendência negativa confirmada. Caso não houvesse condições de confirmar tendência o sinal (?) foi adotado.

O comportamento da T-méd. em São Gabriel da Cachoeira na estação MAM, mostrado nas Figs. 2a e 2b, confirmou tendência positiva $(+)(+)$. Isso se deve porque ao aplicar o teste de Mann-Kendall registrou-se um cruzamento das curvas estatísticas $U\left(t_{n}\right)$ e $U^{*}\left(t_{n}\right)$ entre os intervalos de confiança em 1979 (Fig. 2a) e, além disso, ao aplicar o teste de Pettitt (Fig. 2b) apresentou início de tendência $(+)(+)$ no ano de 1979. Portanto, a evidência de tendência climática ficou confirmada em 1979.

Na localidade de Resende (Figs. 2c e 2d) não foi confirmada tendência para $T$-méd. na estação SON. Ao analisar o gráfico da Fig. 2c, observa-se que apesar de haver
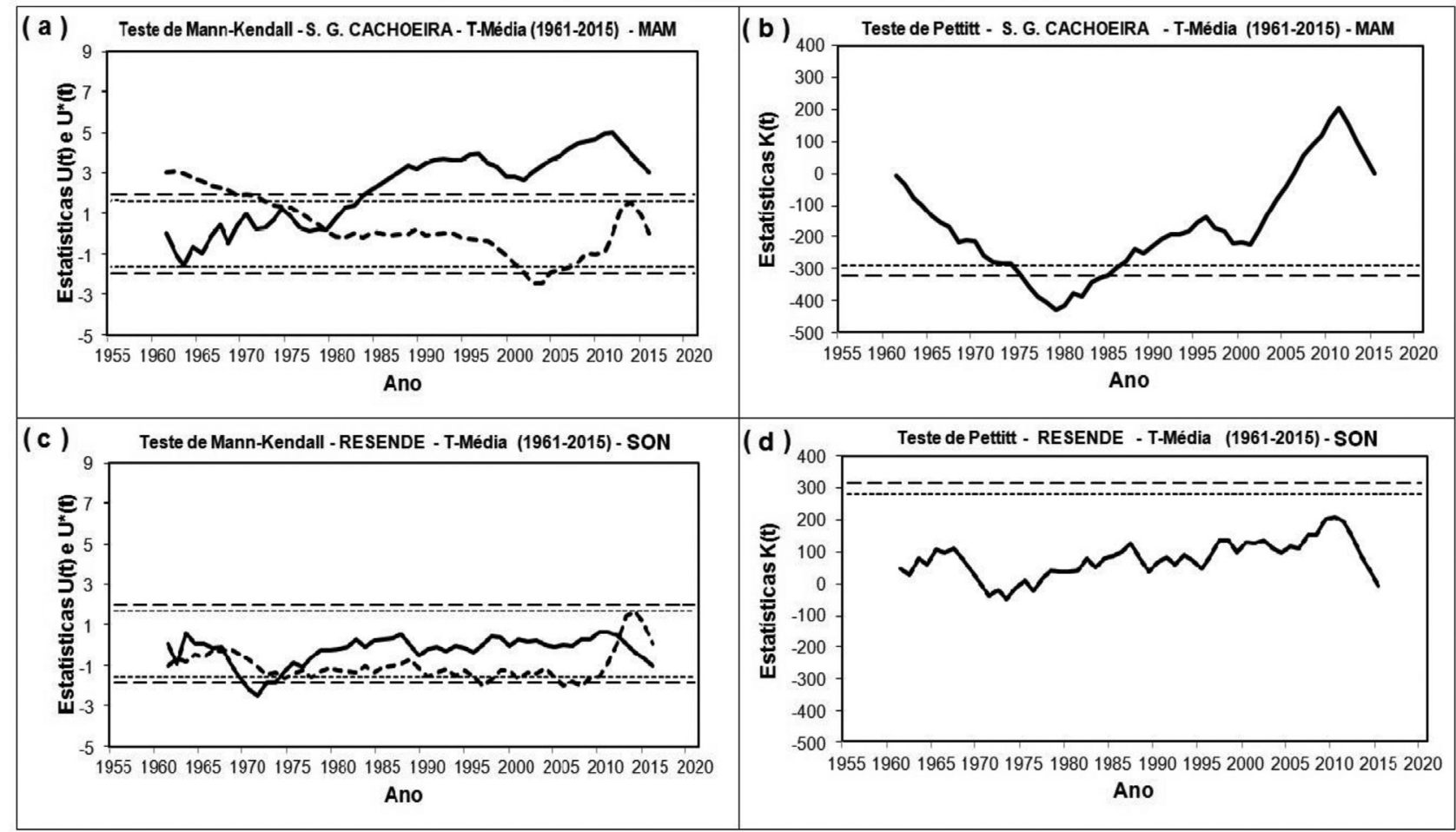

Figura 2 - Resultados gráficos dos testes de Mann-Kendall (à esquerda) e de Pettitt (à direita), respectivamente, para as medidas de: (a) e (b) T-Méd. no outono em São Gabriel da Cachoeira; (c) e (d) T-Méd. na primavera em Resende. 


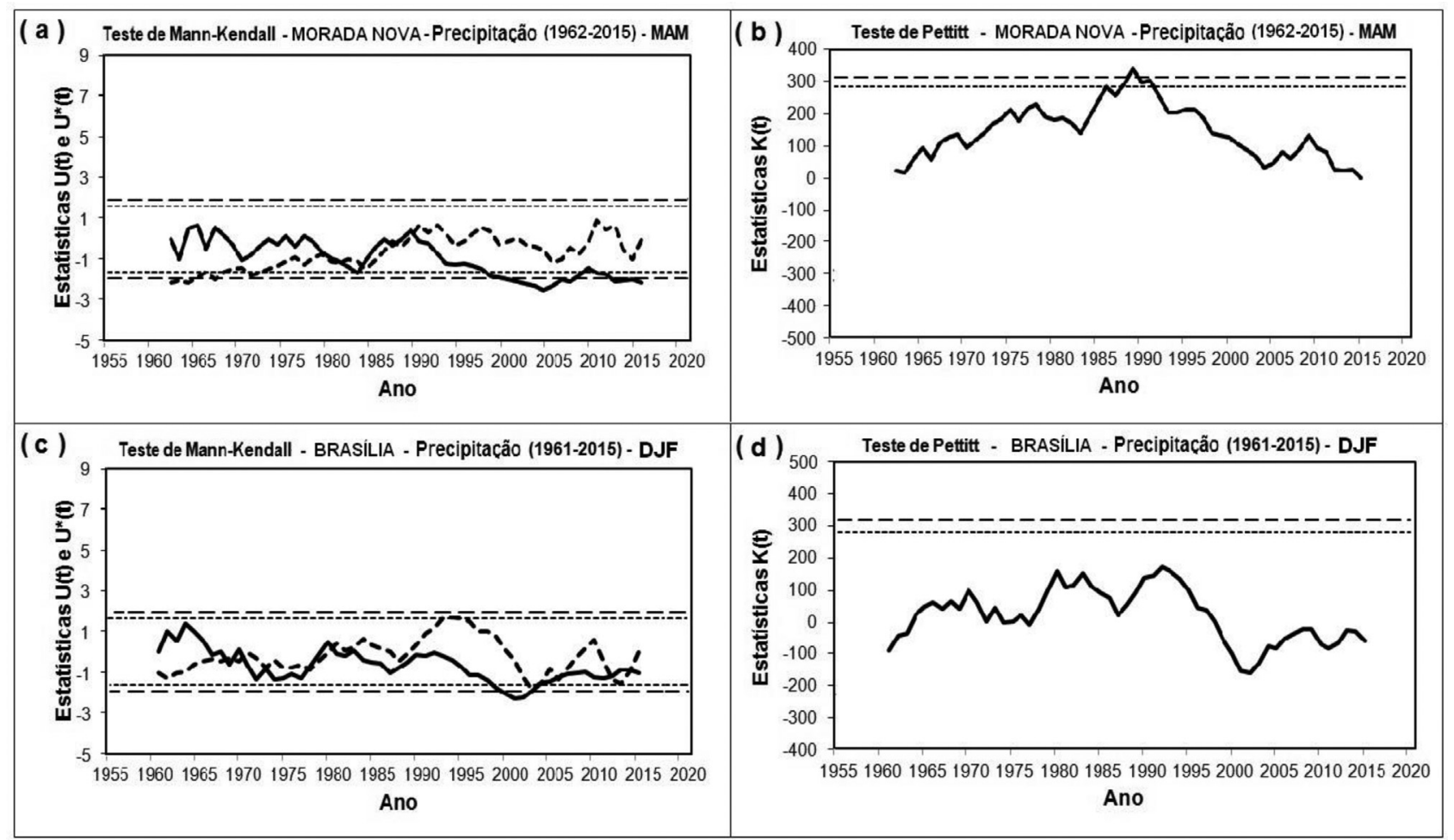

Figura 3 - Idem aos gráficos da Fig. 2, porém aplicados às medidas de Prec.: (a) e (b) no outono em Morada Nova, e (c) e (d) no verão em Brasília.

cruzamentos das curvas estatísticas $U\left(t_{n}\right)$ e $U^{*}\left(t_{n}\right)$ entre os intervalos de confiança de $\pm 5 \%$ e $\pm 10 \%$ em 1967 e 2011 , a curva $K(t)$ do teste de Pettitt, mostrado na Fig. 2d, em nenhum momento cruzou um dos dois níveis de significância, descartando a possibilidade de tendência para aquela localidade.

Com relação à Prec. observada em Morada Nova (Figs. 3a e 3b), a aplicação dos testes não paramétricos na estação MAM indicam tendências negativas (-)(-) a partir de 1989. Isso ocorre devido ao cruzamento das curvas estatísticas $U\left(t_{n}\right)$ e $U^{*}\left(t_{n}\right)$ entre os intervalos de confiança em 1989 (Fig. 3a), além de a curva $K(t)$ do teste de Pettitt ter apresentado o início de tendência (-)(-) confirmada no ano de 1989 (Fig. 3b).
Em contrapartida, apesar dos cruzamentos revelados na Fig. 3c para as curvas estatísticas no teste de MannKendall, não se pode confirmar tendência na Prec. durante a estação DJF para a capital do país, Brasília. Isso ocorre porque a curva da estatística $K(t)$ do teste de Pettitt (Fig. 3d) não cruzou nenhum dos níveis de significância, diagnosticando a inexistência de tendência para o Distrito Federal.

As Tabelas 2 e 3 apresentam, respectivamente para as quatro estações do ano os resultados dos testes estatísticos aplicados para as localidades abordadas em cada bioma do Brasil. Nessas tabelas adotou-se a convenção de sinais discutida anteriormente.

Com exceção das localidades dos biomas Pampa e Pantanal, destaca-se que o número de localidades que regis-

Tabela 2 - Quantidade de cidades estudadas, em cada bioma do Brasil, classificadas quanto à tendência climática identificada pelos testes estatísticos de Mann-Kendall e de Pettitt aplicados para T-Méd. em cada estação do ano.

\begin{tabular}{|c|c|c|c|c|c|c|c|c|c|c|c|c|}
\hline \multirow[t]{2}{*}{ Bioma brasileiro } & \multicolumn{3}{|c|}{ MAM } & \multicolumn{3}{|c|}{ JJA } & \multicolumn{3}{|c|}{ SON } & \multicolumn{3}{|c|}{ DJF } \\
\hline & $(-)$ & $(+)$ & $(?)$ & $(-)$ & $(+)$ & (?) & $(-)$ & $(+)$ & $(?)$ & $(-)$ & $(+)$ & (?) \\
\hline Amazônia & 0 & 22 & 19 & 0 & 18 & 23 & 0 & 19 & 22 & 0 & 30 & 11 \\
\hline Caatinga & 0 & 8 & 46 & 4 & 6 & 44 & 4 & 5 & 45 & 1 & 12 & 41 \\
\hline Cerrado & 2 & 24 & 44 & 1 & 36 & 33 & 0 & 36 & 34 & 2 & 30 & 38 \\
\hline Mata Atlântica & 3 & 16 & 45 & 2 & 21 & 41 & 0 & 17 & 47 & 0 & 17 & 47 \\
\hline Pampa & 0 & 2 & 9 & 0 & 0 & 11 & 0 & 2 & 9 & 0 & 3 & 8 \\
\hline Pantanal & 0 & 0 & 3 & 0 & 0 & 3 & 0 & 1 & 2 & 1 & 0 & 2 \\
\hline Total & 5 & 72 & 166 & 7 & 81 & 155 & 4 & 80 & 159 & 4 & 92 & 147 \\
\hline
\end{tabular}


Tabela 3 - Idem à tabela anterior, porém aplicados para variável climática de Prec.

\begin{tabular}{|c|c|c|c|c|c|c|c|c|c|c|c|c|}
\hline \multirow[t]{2}{*}{ Região Política } & \multicolumn{3}{|c|}{ MAM } & \multicolumn{3}{|c|}{ JJA } & \multicolumn{3}{|c|}{ SON } & \multicolumn{3}{|c|}{ DJF } \\
\hline & $(-)$ & $(+)$ & $(?)$ & $(-)$ & $(+)$ & $(?)$ & $(-)$ & $(+)$ & $(?)$ & $(-)$ & $(+)$ & (?) \\
\hline Amazônia & 1 & 8 & 32 & 1 & 2 & 38 & 4 & 2 & 35 & 0 & 6 & 35 \\
\hline Caatinga & 1 & 0 & 53 & 0 & 5 & 49 & 2 & 1 & 51 & 3 & 3 & 48 \\
\hline Cerrado & 1 & 9 & 60 & 6 & 2 & 62 & 7 & 1 & 62 & 1 & 2 & 67 \\
\hline Mata Atlântica & 0 & 5 & 59 & 1 & 5 & 58 & 2 & 4 & 58 & 1 & 7 & 56 \\
\hline Pampa & 1 & 2 & 8 & 0 & 0 & 11 & 0 & 1 & 10 & 1 & 1 & 9 \\
\hline Pantanal & 0 & 0 & 3 & 0 & 0 & 3 & 0 & 0 & 3 & 0 & 0 & 3 \\
\hline Total & 4 & 24 & 215 & 8 & 14 & 221 & 15 & 9 & 219 & 6 & 19 & 218 \\
\hline
\end{tabular}

traram tendência de aumento na T-Méd. (Tabela 2) nas quatro estações é maior que o número de localidades com tendência de diminuição.

No caso da Prec. (Tabela 3), observa-se tendência de aumento em maior número de localidades do que tendência de diminuição nas estações MAM, JJA e DJF. Para a estação SON observou-se tendência de diminuição em 9 localidades e de aumento em 15.

Constatou-se também que tanto para a T-Méd. como para a Prec. em todas as estações do ano, a quantidade de localidades que acusaram ausência de tendência é superior àquelas localidades com tendência significativa. Vincent $e t$ al. (2005), em estudo similar de tendências sazonais de temperaturas pela América do Sul, também observaram grande número de estações meteorológicas com ausências

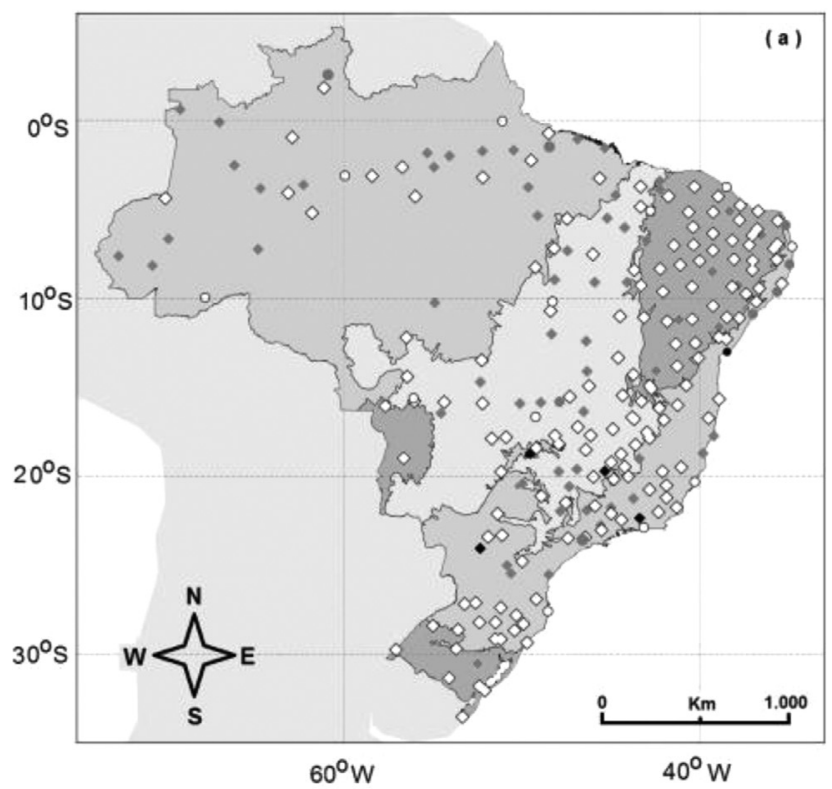

de tendências significativas: do total de 68 estações analisadas, entre 33 a 51 estações não acusaram tendências.

Como foram tratadas neste levantamento um total de 1944 séries temporais, a quantidade de informações numéricas é muito grande. Neste contexto, optou-se por elaborar mapas das distribuições espaciais de tendências dos parâmetros T-Méd. e Prec. nos biomas brasileiros.

\subsection{Mapas das distribuições das tendências}

\subsubsection{Mapas do outono (MAM)}

A Fig. 4a revela 77 (31,69\% do total) localidades em que se registraram tendências na $T$-méd. durante a estação MAM. Dessas localidades, em 72 (29,63\%) ocorreram tendências positivas, $5(2,06 \%)$ negativas e $166(68,31 \%)$ não

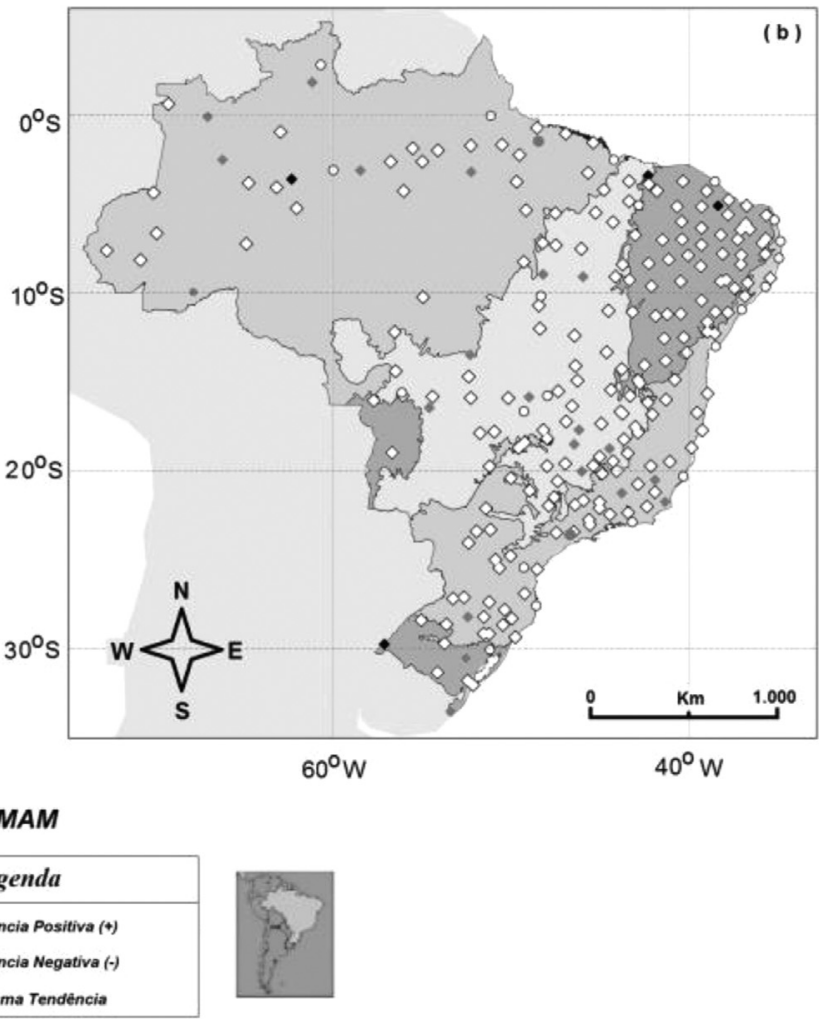

Figura 4 - Mapas das distribuições de tendências no outono (MAM) para: a) T-Méd. e b) Prec. 
acusaram tendências. Observa-se que as detecções positivas e a ausência de tendência estão distribuídas de forma aleatória pelos biomas brasileiros. Constata-se que tendências negativas foram registradas em algumas cidades dos biomas Mata Atlântica e Cerrado.

Com relação à Prec. (Fig. 4b), verifica-se um número de $215(88,48 \%)$ localidades que não apresentaram tendências na estação MAM. Essa quantidade foi bem superior aos $24(9,88 \%)$ locais que registraram índices positivos, ou ao $4(1,65 \%)$ com índices negativos de tendências. Neste sentido, observa-se que os municípios que registraram tendência de diminuição de chuvas estão localizados em quatro biomas: Amazônia, Cerrado, Caatinga e Pampa. As cidades em que se observou tendência de aumento de chuvas estão distribuídas pelos biomas Amazônia, Cerrado, Mata Atlântica e Pampa.

Os resultados aqui obtidos corroboram com os conquistados por Xavier et al. (1994) que constataram, no período de 1933 a 1986, aumento nas precipitações entre fevereiro e maio na capital São Paulo (bioma Mata Atlântica). Adicionalmente, Borges et al. (2014) comparam os períodos de 2001 a 2010 com 1971 a 2000 na região Central do país (bioma Cerrado) e observaram diminuição evidente na precipitação acumulada nas estações do inverno e outono.

\subsubsection{Mapas do inverno (JJA)}

Para a estação JJA (Fig. 5a), 81 (33,33\%) localidades registraram aumento da $T$-méd., enquanto que 7 (2,88\%) acusaram tendência negativa e 155 (63,79\%) não acusaram tendência. Neste sentido, verifica-se que nos biomas Pampa e Pantanal ocorreu total ausência de variação acentuada na temperatura, enquanto que nos demais biomas observaram-se locais com tendências. As diminuições de T-méd. foram observadas no Cerrado, na Caatinga e na Mata Atlântica.

Com relação à Prec. (Fig. 5b), verifica-se que 221 (90,95\%) localidades não apresentaram tendências na estação JJA. Aumentos no índice de chuva foram inferidos para 14 (5,76\%) localidades distribuídas na Amazônia, Cerrado, Caatinga e Mata Atlântica. Ao passo que as diminuições de tendências foram observadas em 8 (3,29\%) locais distribuídos no bioma Amazônia, Cerrado e Mata Atlântica.

De acordo com Rao et al. (2016), na região norte da Amazônia há uma tendência significativa de diminuição da precipitação na estação do ano mais seca, ou seja, no inverno, analisada no período de 1979 a 2011. Para esse mesmo período, na região sudeste do país, que compreende o bioma Mata Atlântica, esses autores também verificaram tendência de diminuição de precipitação na estação seca do ano. Com relação a região central do país (bioma Cerrado), Borges et al. (2014) comparam os períodos de 2001 a 2010 com 1971 a 2000 e observaram diminuição evidente na precipitação acumulada nas estações do inverno e outono.
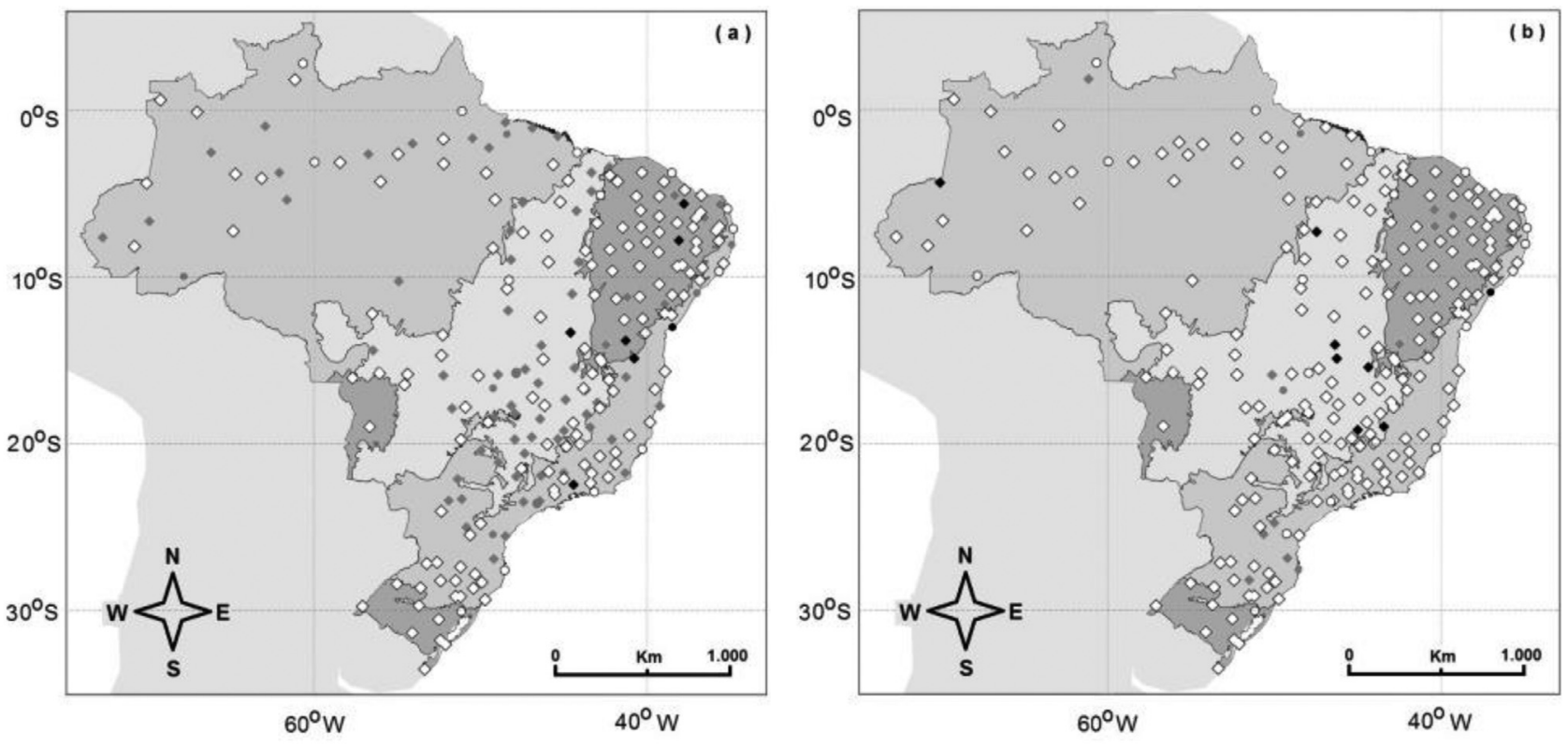

JJA
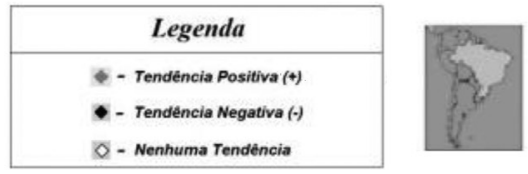

Figura 5 - Idem a figura anterior, mas no inverno (JJA) para: a) T-Méd. e b) Prec. 


\subsubsection{Mapas da primavera (SON)}

Na Fig. 6a observou-se para a T-méd. um total de 80 $(32,92 \%)$ localidades com tendência de aumento, 4 $(1,65 \%)$ com tendência de diminuição e 159 (65,43\%) com ausência de tendência na estação SON. Verificou-se que em todos os biomas há ocorrência de tendência positiva e apenas no bioma Caatinga é que foram inferidas tendências negativas. Ausência de tendências para essa variável climática foi identificada em todos os biomas brasileiros, com destaque para as cidades litorâneas.

Com relação à Prec. na estação SON (Fig. 6b), novamente destaca-se o número de localidades sem ocorrências de tendências, sendo um total de 219 (90,12\%). Entretanto, há um total de $15(6,17 \%)$ locais com tendência negativa, o que é maior que $9(3,70 \%)$ de tendência positiva, fato esse contrário ao registrado nas estações avaliadas anteriormente. Observa-se que o maior número de locais com diminuição de chuvas ocorreu nos biomas Cerrado, Amazônia e Mata Atlântica. Tendências de aumento de chuvas foram inferidas, respectivamente, na Mata Atlântica, Amazônia, Cerrado e Pampa. As ausências de tendências se encontram espalhadas por todos os biomas.

Cordeiro et al. (2016) observaram aumento da temperatura média, máxima e mínima do ar na região sul do país (bioma Pampa) no período de 1950 a 2009 em 14 diferentes localidades. Minuzzi e Caramori (2011) estudaram tendências de chuva em diferentes localidades no estado do Paraná (bioma Mata Atlântica), com período

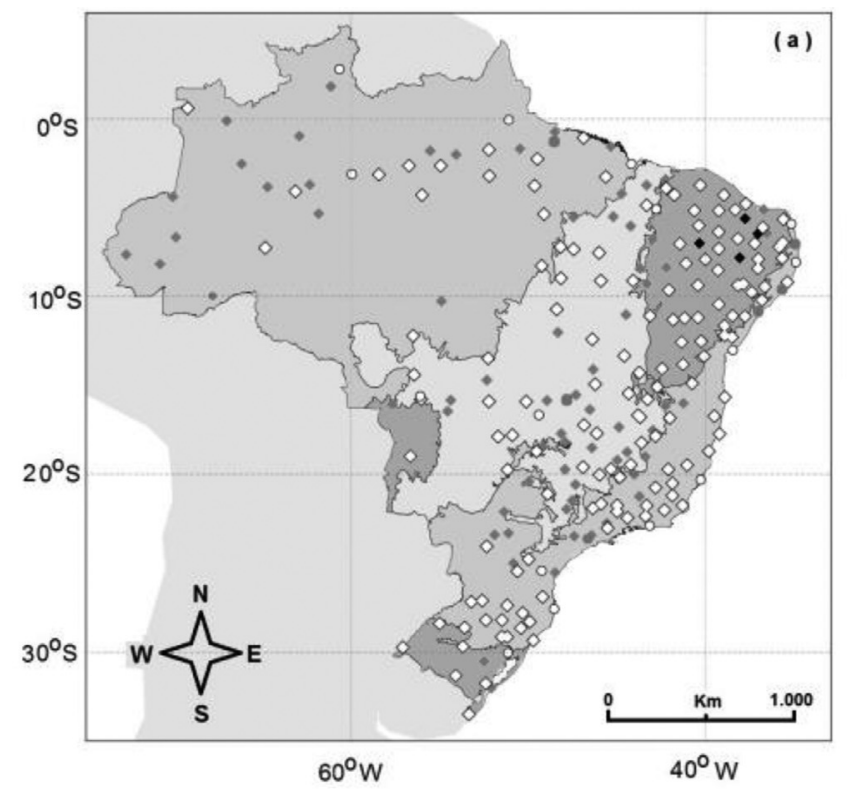

variáveis entre 1945 a 2006 e verificaram tendências negativas significativas para a ocorrência de veranicos (chuva com duração de 5 a 10 dias e quantidade acumulada inferior a $10 \mathrm{~mm}$ ) na primavera.

\subsubsection{Mapas do verão (DJF)}

Na estação DJF (Fig. 7a) observou-se para a T-Méd. um total de 92 (37,86\%) tendências positivas, 4 (1,65\%) tendências negativas e 147 (60,49\%) localidades que não acusaram tendência. Em cinco biomas constatou-se a ocorrência de tendência positiva, sendo eles Amazônia, Cerrado, Caatinga, Mata Atlântica e Pampa. Quanto as tendências negativas, observou-se sua presença nos biomas Pantanal, Cerrado e Caatinga. Da mesma forma que em outras estações do ano anteriormente analisadas, a ausência de tendências para a $T$-Méd. foi identificada em todos os biomas.

A Prec. na estação DJF (Fig. 7b) apresentou 218 $(89,71 \%)$ localidades sem ocorrências de tendências, 19 $(7,82 \%)$ locais com tendência positiva e $6(2,47 \%) \mathrm{com}$ tendência negativa. Neste contexto, observa-se na Fig. $7 \mathrm{~b}$ que o maior número de locais com aumento de chuvas ocorreu da Mata Atlântica (6), na Amazônia (5), Caatinga (3), Cerrado (2) e o Pampa (1). Nenhuma tendência de Prec. foi inferida no bioma Pantanal e 4 locais acusaram tendência de diminuição de chuvas, estando eles no Pampa, Mata Atlântica, Caatinga e Cerrado. No verão, as ausências

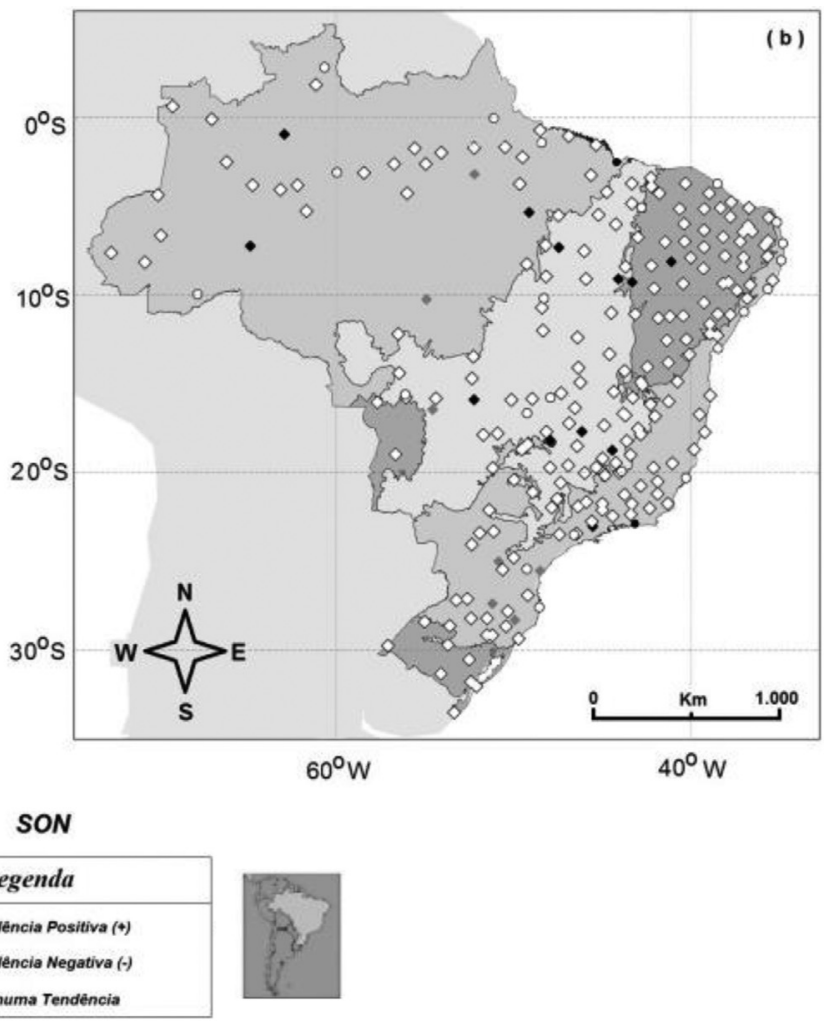

Figura 6 - Idem a figura anterior, mas na primavera (SON) para: a) T-Méd. e b) Prec. 


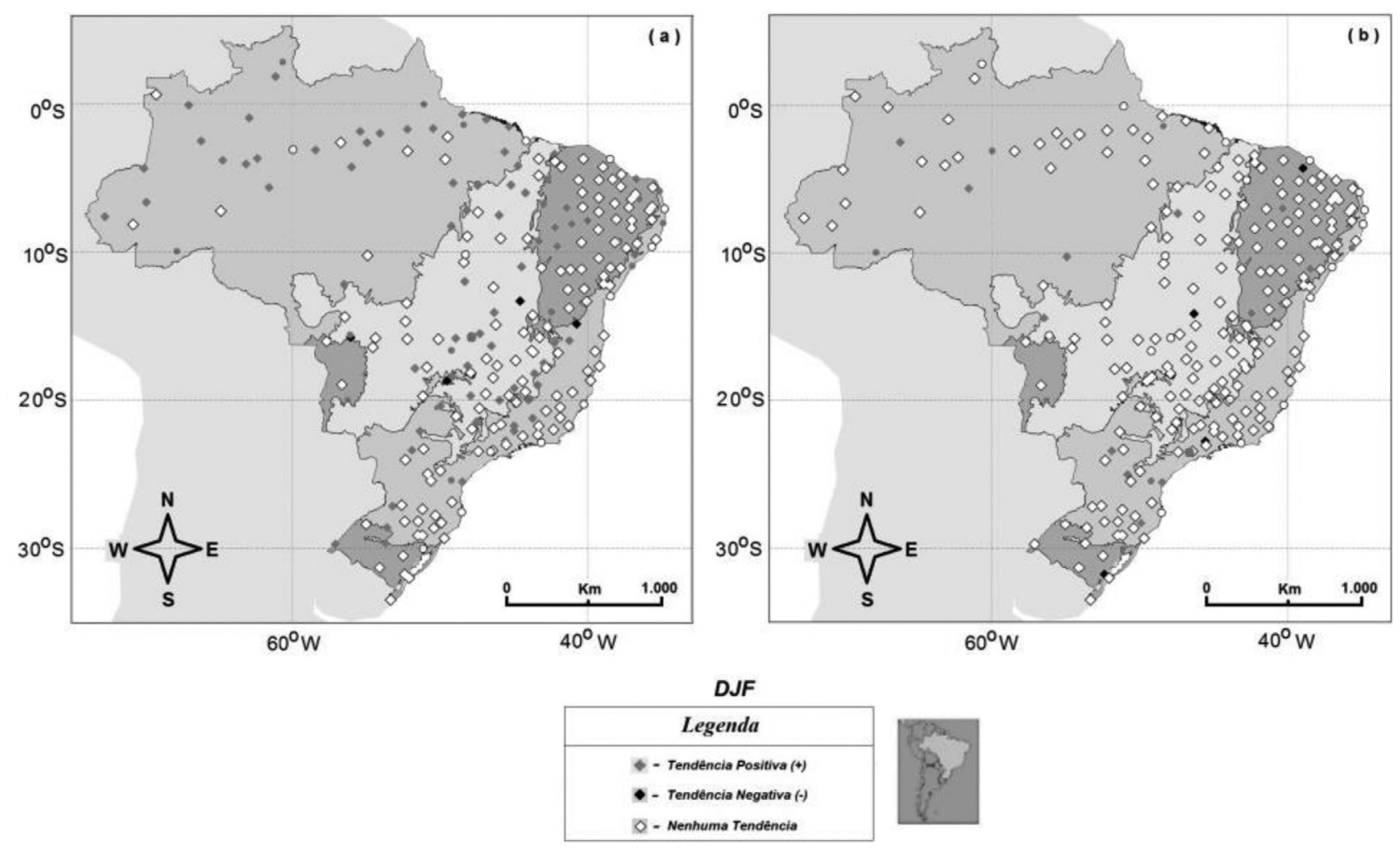

Figura 7 - Idem a figura anterior, mas no verão (DJF) para: a) T-Méd. e b) Prec.

de tendências da Prec. se distribuem por todos os biomas do Brasil.

Liebmann et al. (2004) verificaram que a região centro-sul do Brasil, que compreende os biomas Cerrados, Mata Atlântica e Pampa, apresentam tendências significativas aumento nas precipitações de verão entre 1976 e 1999 e entre 1948 e 75 . Os autores atribuíram essa tendência positiva a um aumento no número de dias chuvosos, associados a um aumento nas temperaturas da superfície do Atlântico adjacente. Adicionalmente, ressalta-se que esses dois períodos analisados 1976-99 e 1948-75 são coincidentes com uma fase quente e uma fase fria da Oscilação Decenal do Pacífico (ODP).

Esses resultados corroboram com os de Back (2001), que estudou a precipitação mensal de Urussanga (bioma Mata Atlântica) no período de 1924 a 1998 e verificou tendência de aumento dessa variável no mês de janeiro. Adicionalmente, Sansigolo e Kayano (2010) verificaram tendência positiva para a precipitação de verão no período de 1913 a 2006 na região Sul do Brasil, que compreende o bioma Pampa. Pereira et al. (2004) e Xavier et al. (1994) mostraram que as precipitações de verão estão se intensificando na Região Metropolitana de São Paulo (RMSP; bioma Mata Atlântica), devido à efeitos da ilha de calor urbana associada à circulação da brisa marítima. Xavier et al. (1994) constataram no período de 1933 a 1986 um aumento nas precipitações mais intensas em fevereiro e maio. Raimundo et al. (2014) analisaram as tendências anuais e de verão das classes de totais de precipitação leve, moderada e intensa em 21 estações pluviométricas da RMSP (bioma Mata Atlântica) com séries de dados de diferentes comprimentos no período de 1888 a 2004. Os autores constataram tendências positivas nos totais anuais em 9 estações na área central da RMSP, mas somente em 4 ocorreram no verão.

Rao et al. (2016) documentaram que na região norte da Amazônia há uma tendência significativa de aumento da precipitação na estação do ano mais chuvosa (verão), analisada no período de 1979 a 2011. Para esse mesmo período na região sudeste do país, que compreende o bioma Mata Atlântica, os autores verificaram tendência de diminuição de precipitação na estação do ano chuvosa. Borges et al. (2014) comparam os períodos de 2001 a 2010 com 1971 a 2000 na região Central do país (bioma Cerrado) e observaram aumento aparente na precipitação acumulada na estação do ano mais chuvosa, ou seja, no verão.

\subsection{Frequências temporais das tendências identificadas}

Nos histogramas apresentados na Fig. 8 são mostradas as frequências totais de tendências inferidas, ou seja, a soma das tendências positiva e negativa, para um determinado parâmetro climático.

Nas estações MAM e DJF (Figs. 8a e 8d, respectivamente) observa-se que nas décadas de 1960 e 1970 foram registradas as menores quantidades de tendências. No caso 

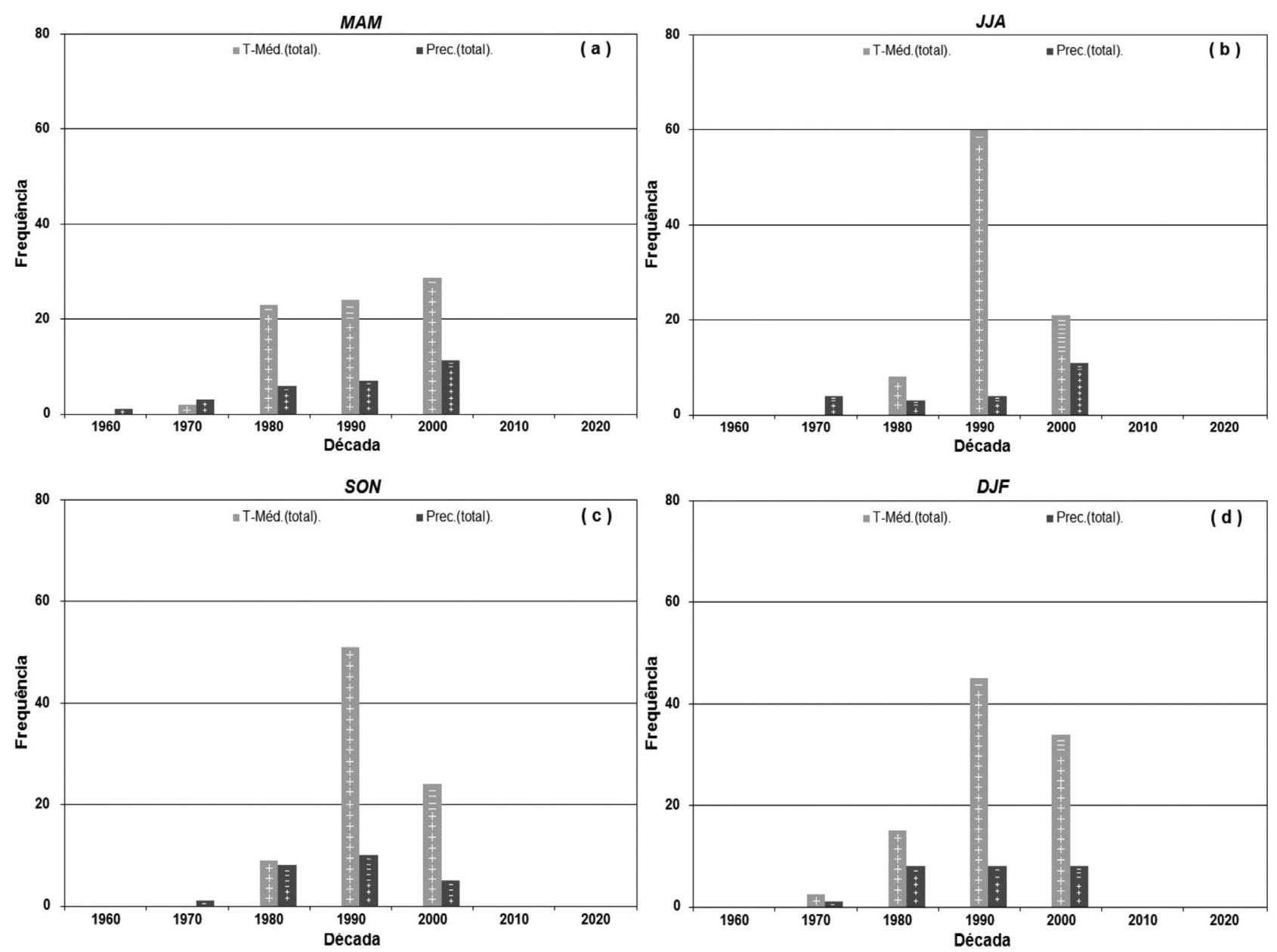

Figura 8 - Histogramas com as contagens de tendências em relação às décadas em que as mesmas ocorreram para a T-Méd. (em cinza) e Prec. (em preto) tratadas em: a) outono (MAM); b) inverno (JJA); c) primavera (SON) e d) verão (DJF).

da $T$-Méd., as maiores quantidades de tendências, principalmente positivas, foram registradas na década de 1990 para as outras estações (JJA, SON e DJF, em cinza e, respectivamente, nas Figs. 8b, 8c e 8d), destacando a primavera (SON) em 1992, o verão (DJF) em 1993 e, particularmente com maior número de tendências, o inverno (JJA) em 1997. Observa-se que nas décadas de 1980 a 2000, em todas as estações do ano, foram aferidas diminuições de T-Méd., porém em pouca quantidade.

Com relação à Prec. as maiores quantidades de tendências foram identificadas nas décadas de 1990 a 2000, com destaque para os aumentos ao longo de MAM e JJA (em preto e respectivamente nas Figs. 8a e 8b) na década de 2000 para todas as localidades analisadas nos biomas brasileiros. No entanto, diminuições nos índices de chuvas aconteceram com maior ênfase em SON e DJF (em preto; Figs. 8c e 8d) nas décadas de 1990 e 2000.

$\mathrm{O}$ clima dos biomas brasileiros, assim como em outras partes do mundo, é muito complexo, pois envolve controles internos e externos ao sistema terra-atmosferaoceanos. Dentre os principais controladores externos, estão a variação da produção de energia do Sol, as mudanças dos parâmetros orbitais da Terra e a tectônica de placas. No caso do controlar interno, mas que pode sofrer influências externas, está o denominado albedo planetário, cuja variação controla o fluxo de energia solar que penetra no planeta (Molion, 2008).

Certamente, pelo o que foi exposto anteriormente, não existe um aval para que os seres humanos degradem o meio ambiente, como infelizmente tem ocorrido nas últimas décadas, em particular no bioma Amazônia, parte do Pantanal e Cerrado. Ao contrário, pois considerando que o aumento populacional nas próximas décadas é inevitável, sugere-se a adoção de políticas de conservação ambiental bem elaboradas e mudanças nos hábitos de consumo para que as gerações futuras possam dispor dos recursos naturais que se dispõem atualmente (Zanquim Jr. et al., 2015).

Uma possível explicação para as tendências detectadas nas variáveis climáticas observadas parece estar relacionada às características geográficas e biodiversidades de cada bioma. Adicionalmente, deve-se reconhecer que a mudança na concepção da vida rural para a vida urbana 
proporcionou um desenvolvimento econômico-social e permitiu os avanços tecnológicos vivenciados. Porém, essa gama de elementos impulsionou crises ambientais, em especial nas regiões próximas aos centros urbanos. Rao et al. (2016) apontam que as tendências negativas na precipitação que tem sido observada na região sudeste do país (bioma Mata Atlântica) possuem forte impacto na geração de energia hidroelétrica, não somente para essa região do país, mais a nível nacional pois as barragens geram energia que é distribuída para todo o país. Os autores comentam ainda que o aumento da precipitação na região norte da Amazônia está provavelmente associado com o aquecimento do oceano Atlântico, que resulta em maior transporte de humidade vindo do Leste. A diminuição da precipitação na região sudeste do país (bioma Mata Atlântica) pode estar associada com a diminuição dos sistemas produtores de chuva no Sul devido ao aumento da pressão atmosférica ao nível médio do mar no sul do país.

Marengo et al. (2017) ressaltam que a disponibilidade de água no Brasil é diretamente relacionada com o clima, especialmente nos meses de verão. Atrasos no começo do período chuvoso anual pode afetar a agricultura e a geração de energia hidroelétrica. A ocorrência de enchentes e secas tem causado grandes impactos na economia do país e para a população. Alterações nos padrões da precipitação podem também afetar os fluxos dos rios. A região do rio São Francisco, no bioma Caatinga tem sido muito afetada pela diminuição de precipitação, resultando em impactos severos na irrigação e na geração de energia hidroelétrica.

Considerando o cenário de aumento da temperatura média nas estações do ano do inverno, primavera e verão nos biomas Amazônia e Cerrado observadas no presente estudo e possível diminuição de precipitação em todas as estações do ano em todos os biomas brasileiros, porém em regiões isoladas, os resultados do presente estudo corroboram com o de Nobre et al. (2005) que estudaram os impactos de alterações climáticas nos biomas brasileiros, considerando os cenários do IPCC para o período 20002100 e verificaram, de forma geral, a desertificação do semi-árido nordestino, isto é, um clima quente e muito seco com índices pluviométricos inferiores a $250 \mathrm{~mm}^{\mathrm{ano}} \mathrm{o}^{-1}$, e a "savanização" da Amazônia, em que todos os meses apresentariam temperatura média mensal superior a $18{ }^{\circ} \mathrm{C}$. Medlyn e McMurtrie (2005) ressaltam a possibilidade de significativa perda de biodiversidade pela dificuldade de adaptação desses biomas a mudanças climáticas que ocorreriam em poucas décadas.

A ocorrência de fenômenos naturais como El NiñoOscilação Sul (ENOS) tem apresentado aumento na frequência de ocorrência e intensidade (IPCC, 2013). Conforme argumentam Guimarães e Reis (2012), os eventos de El Niño contribuem para os aumentos das temperaturas máximas e mínimas em 265 cidades espalhadas pelo Brasil (estações convencionais do BDMEP; medidas entre 19602010). O inverso ocorre em eventos de La Niña para essas mesmas localidades, exceto para a região Amazônica. Em anos de existência do evento La Niña ocorrem diminuições das temperaturas do ar em quase todas as regiões do Brasil. Ainda conforme os autores, o impacto do fenômeno ENOS no país se faz mais presente nos meses de inverno e primavera. Marengo (2006) ressalta que impactos do fenômeno El Niño e La Niña têm sido observados nas regiões do país, mais intensamente nas regiões Norte, Nordeste (secas durante El Niño nos biomas Amazônia, Caatinga e região norte do Cerrado) e Sul do Brasil (secas durante La Niña e excesso de chuva e enchentes durante El Niño nos biomas Pampa e sul da Mata Atlântica). Barros et al. (2002) ressaltam que o El Niño causa impacto considerável nos padrões de temperatura na região sul da América do Sul, que engloba o bioma Pampa no Brasil. Cordeiro et al. (2016) observaram tendências de aumento das temperaturas média, máxima e mínima no sul do país (bioma Pampa) e relacionaram parte dessa alteração com o fenômeno El Niño, especialmente a fase quente,, pois ocorreu de forma mais frequentes e extensa a partir da década de 1980, principalmente na primavera e início do verão. No entanto, os autores ressaltam que as alterações na temperatura são também coerentes com o aumento do efeito estufa na atmosfera e com o aquecimento do sistema climático global e regional.

Em princípio, os dados aqui tratados parecem estar relacionados aos eventos El Niño e La Niña, pois para a T-Méd., os períodos dos aumentos de tendências registradas na década de 1990 para as estações JJA (em 1997), SON (em 1992) e DJF (em 1993) e as diminuições de tendências observa-se que nas décadas de 1980 a 2000, estão em consonância com os períodos relatados por Firpo et al. (2012), para os referidos eventos climáticos globais. Também pode-se presumir que, além dos eventos naturais, as tendências aqui registradas podem estar relacionadas às oscilações registradas têm caráter regional de algumas localidades, devido ação antropogênica (Zanquim Jr. et al., 2015; Pellegrino et al., 2007) constatam, por meio da Declaração sobre Florestas da Conferência do Rio, a Agenda 21 e dos Objetivos do Milênio, que as ações antrópicas são responsáveis por grande parte das mudanças climáticas que se detectam hoje e que se projetam para o futuro. Os autores ressaltam que o modelo de desenvolvimento agrícola do Brasil tem provocado grandes impactos ambientais negativos. A emissão de gases de efeito estufa a partir das queimadas, desmatamento e expansão agrícola é muito maior do que a industrial e da queima de combustíveis fósseis e o país tem sido considerado como um dos maiores emissores do mundo. Ressalta-se que devido a variabilidade natural do clima, tendências observadas em series de curto comprimento são bastante sensíveis às datas de começo e fim e geralmente não refletem tendências climáticas de longo termo (IPCC, 2013).

Todos esses fatores precisam ser conhecidos e devidamente estudados não só para efeito de previsão do tempo, 
mas, especialmente, para o entendimento das alterações climáticas naturais e, consequentemente, para que, à luz do conhecimento, possamos saber exatamente onde está o impacto da ação do ser humano e separar seus efeitos nas mudanças do clima.

\section{Conclusões}

Tendências sazonais na temperatura e na precipitação foram observadas em todo o Brasil. O número de estações meteorológicas que apresentaram tendências significativas foi sempre muito menor do que o número de estações meteorológicas em que não se detectaram tendências significativas.

Dentre as tendências observadas, a temperatura média mensal foi a variável em que se registrou maior número de estações meteorológicas com tendência, principalmente de aumento nas estações do inverno, primavera e verão. Os biomas Amazônia e Cerrado foram os mais evidenciados. Poucas tendências negativas foram registradas e se encontram, em geral, na Caatinga e Cerrado.

Para a precipitação pluvial total sazonal, tendências negativas foram registradas nas quatro estações do ano. As tendências positivas foram identificadas durante as estações do outono e inverno.

\section{Agradecimentos}

Os autores fazem seus agradecimentos ao Instituto Nacional de Meteorologia (INMET) pela disponibilização dos dados utilizados neste estudo. Também agradecem ao Conselho Nacional de Desenvolvimento Científico e Tecnológico $(\mathrm{CNPq})$ pelo apoio a esta pesquisa (processo $\mathrm{n}^{\circ}$ 100375/2017-0), além do Observatório Municipal de Campinas Jean Nicolini (OMCJN) e à Pontifícia Universidade Católica de Campinas (PUC-Campinas) pelo apoio estrutural e tecnológico oferecido para a execução do presente trabalho.

\section{Referências}

ANA. Agência Nacional de Águas. Conjuntura dos Recursos Hídricos no Brasil. 2013. Disponível em: www.arquivos.ana.gov.br/institucional/spr/conjuntura/web Site_relatorio Conjuntura/projeto/index.html. Acesso em: 01 de dezembro de 2016.

BACK, A.J. Aplicação de análise estatística para identificação de tendências climáticas. Pesquisa Agropecuária Brasileira, v. 36, n. 5, p. 717-726, 2001.

BARROS, V.R.; GRIMM, A.M.; DOYLE, M.E. Relationship between temperature and circulation in southeastern south America and its influence from El Niño and La Niña events. J. Meteor. Soc. japan, v. 80, p. 21-32, 2002.

BLAIN, G.C. Considerações estatísticas relativas à oito séries de precipitação pluvial da Secretaria de Agricultura e Abastecimento do Estado de São Paulo. Revista Brasileira de Meteorologia, v. 24, n. 1, p. 12-23, 2009.
BLAIN, G.C. Séries anuais de temperatura máxima média do ar no Estado de São Paulo: variações e tendências climáticas. Revista Brasileira de Meteorologia, v. 25, n. 1, p. 114-124, 2010.

BORGES, P.A.; FRANKE, J.; SILVA, F.D.S.; WEISS, H.; BERNHOFER, C. Differences between two climatological periods (2001-2010 vs. 1971-2000) and trend analysis of temperature and precipitation in central Brazil. Theoretical and Applied Climatology, v. 116, n. 1, p. 191-202, 2014.

CORDEIRO, A.P.A.; BERLATO, M.A.; FONTANA, D.C.; ALVES, R.C.M. Tendências climáticas das temperaturas do ar no estado do Rio Grande do Sul, Sul do Brasil. Revista Brasileira de Geografia Física, v. 9, n. 3, p. 868-880, 2016.

FIRPO, M.A.F.; SANSIGOLO, C.A.; DE ASSIS, S.V. Climatologia e variabilidade sazonal do número de ondas de calor e de frio no Rio Grande do Sul associadas ao ENOS. Revista Brasileira de Meteorologia, v. 27, n. 1, p. 95-106, 2012.

GROPPO, J.D.; MORAES, J.M.; BEDUSCHI, C.E.; MARTINELLI, L.A. Análise de séries temporais de vazão e precipitação em algumas bacias do Estado de São Paulo com diferentes graus de intervenções antrópicas. Geociências, v. 24, n. 2, p. 181-193, 2005.

GUIMARÃES, D.P.; REIS, R. dos. Impactos do fenômeno Enos sobre a temperatura no Brasil. Revista Espinhaço, v. 1, n. 1, p. 34-40, 2012.

IBGE. Instituto Brasileiro de Geografia e Estatística. Censo Demográfico de 2010. Disponível em: www.cidades.ibge.gov.br/xtras/home.php. Acesso em: 14 de fevereiro de 2017.

INMET. Instituto Nacional de Meteorologia. Banco de Dados para Pesquisa e Ensino (BDMEP). Disponível em: http://inmet.gov.br. Acesso em: 09 de novembro de 2016.

IPCC - Intergovernmental Panel on Climate Change (2013). Climate Change: The Physical Science Basis. Contribution of Working Group I to the Fifth Assessment Report of the Intergovernmental Panel on Climate Change.. Cambridge University Press: Cambridge, United Kingdom and New York, NY, USA, 1535 p., 2013.

LIEBMANN, B.; VERA, C.S.; CARVALHO, L.M.V.; CAMILLONI, I.; HOERLING, M.P.; BARROS, V.R.; BAEZ, J.; BIDEGAIN, M. An observed trend in central South American precipitation. Journal of Climate, v. 17, p. 4357-4367, 2004.

MARENGO, J.A. Mudanças climáticas globais e seus efeitos sobre a biodiversidade: caracterização do clima atual e definição das alterações climáticas para o território brasileiro ao longo do século XXI. MMA, Ministério do Meio Ambiente, 2006.

MARENGO, J.A.; TOMASEllA, J.; NOBRE, C.A. Climate Change and Water Resources. Waters of Brazil, p. 171186, 2017.

MEDLYN, B.E.; MCMURTRIE, R.E. Effects of CO2 on Plants at Different Timescales. In: Ehleringer, J. R., Cerling, T. E. e Dearing, D. M. (ed.) - A History of Atmospheric CO2 and Its Effects on Plants, Animals, and Ecosystems. Springer. New York. USA., 530 p., 2005.

MINUZZI, R.B.; CARAMORI, P.H. Variabilidade climática sazonal e anual da chuva e veranicos no Estado do Paraná. Revista Ceres, v. 58, n. 5, p. 593-602, 2011.

MMA. Ministério do Meio Ambiente. Conheça os biomas brasileiros - diversidade biológica. Disponível em: 
http://www.brasil.gov.br/meio-ambiente/2009/10/biomas-b rasileiros. Acesso em: 16 de março de 2017.

MOLION, L.C.B. Aquecimento global: uma visão crítica. Revista Brasileira de Climatologia, v. 3, p. 7-24, 2008.

MORAES, J.M.; PELLEGRINO, G.; BALLESTER, M.V.; MARTINELLI, L.A.; VICTORIA, R.L. Estudo preliminar da evolução temporal dos componentes do ciclo hidrológico da bacia do Rio Piracicaba. In: Simpósio Brasileiro de Recursos Hídricos - 11; Simpósio de Hidráulica e Recursos Hídricos dos Países de Língua Oficial Portuguesa - 2; Recife. Anais... Recife: Associação Brasileira de Recursos Hídricos, p. 27-32, 1995.

MORTATTI, J.; BORTOLETTO, M.J.JR.; MILDE, L.C.E.; Probst, J-L. Hidrologia dos rios Tietê e Piracicaba: séries temporais de vazão e hidrogramas de cheia. Revista Ciência \& Tecnologia, v. 12, n. 23, p. 55-67, 2004.

NAGHETTINI, M.C.; PINTO, E.J.A. Hidrologia Estatística. Belo Horizonte: Serviço Geológico do Brasil (C-PRM), 561 p., 2007.

NOBRE, C.A.; ASSAD, E.D.; OYAMA, M.D. Mudança Ambiental no Brasil - O impacto do aquecimento global nos ecossistemas da Amazônia e na agricultura. Scientific American Brasil, v. 12, p. 70-75, 2005.

PENEREIRO, J.C.; MARTINS, L.L.S.; BERETTA, V.Z. Identificação de variabilidades e tendências interanuais em medidas hidro-climáticas na região hidrográfica do TocantinsAraguaia, Brasil. Revista Brasileira de Climatologia, v. 18, p. 219-241. 2016.

PEREIRA FILHO, A.J.; BARROS, M.T.L.; HALLAK, R.; GANDU, A. W. Enchentes na região metropolitana de São Paulo: aspectos de mesoescala e a avaliação de impactos. In: XIII Congresso Brasileiro de Meteorologia, 2004, Fortaleza. Anais... Fortaleza: Associação Brasileira de Meteorologia, 2004.

PBMC. Painel Brasileiro de Mudanças Climáticas. Sumário Executivo: Base Científica das Mudanças Climáticas. Contribuição do Grupo de Trabalho 1 ao Primeiro Relatório de Avaliação Nacional do Painel Brasileiro de Mudanças Climáticas. 2015. Disponível em: http://www.pbmc.coppe.ufrj.br/documentos/MCTI_PBMC Sumario\%20Executivo\%204_Finalizado.pdf. Acesso em: $\overline{2} 3$ de janeiro de 2017.

PELLEGRINO, G.Q.; ASSAD, E.D.; MARIN, F.R. Mudanças Climáticas Globais e a Agricultura no Brasil. Revista Multiciência, v. 8, p. 139-162, 2007.
PETTITT, A.N. A non-parametric approach to the change-point problem. Applied Statistics, v. 28, n. 2, p. 126-135, 1979.

PICKERING, N.B.; HANSEN, J.W.; JONES, J.W.; WELLS, C.M.; CHAN, V.K.; GODWIN, D.C. Weather Man: a utility for managing and generating daily weather data. Agronomy Journal, v. 86, p. 332-337, 1994.

RAIMUNDO, C.C.; SANSIGOLO, C.A.; MOLION, L.C.B. Tendências das classes de precipitação na região metropolitana de São Paulo. Revista Brasileira de Meteorologia, v. 29, n. 3, p. 397-408, 2014.

RAO, V.B.; FRANCHITO, S.H.; SANTO, C.M.E; GAN, M.A. An update on the rainfall characteristics of Brazil: seasonal variations and trends in 1979-2011. International Journal of Climatology, v. 36, n. 1, p. 291-302, 2016.

SANSIGOLO, C.A.; KAYANO, M.T. Trends of seasonal maximum and minimum temperatures and precipitation in Southern Brazil for the 1913-2006 period. Theoretical and Applied Climatology, v. 101, n. 1-2, p. 209-216, 2010.

SNEYERS, R. Sur IAnalyse Statistique dês Séries dObservations. Organisation Météorologique Mondial, 192 p., 1975.

TOLEDO, K. Quinto relatório do IPCC mostra intensificação das mudanças climáticas. Revista da Agência FAPESP, 2013. Disponível em: http://agencia.fapesp.br/17944. Acesso em: 23 de fevereiro de 2017.

VINCENT, L.A.; PETERSON, T.C.; BARROS, V.R.; MARINO, M.B.; RUSTICUCCI, M.; CARRASCO, G.; RAMIREZ, E.; ALVES, L.M.; AMBRIZZI, T.; BERLATO, M.A.; et al. Observed trends in índices of daily temperature extremes in South America 1960-2000. Journal of Climate, v. 18, p. 5011-5023, 2005.

XAVIER, T.M.B.S.; XAVIER, A.F.S.; DIAS, M.A.F.S. Evolução da precipitação diária num ambiente urbano: o caso da cidade de São Paulo. Revista Brasileira de Meteorologia, v. 9, n. 1, p. 44-53, 1994.

ZANQUIM JR., J.W.; MORAES, A.P.H.; MORAES, F.T.; MELNICKY, E.C.C. Danos ambientais urbanos e instrumentos de solução dos conflitos. In: Novos Direitos - Cidades em Crise? 2015. Anais... São Carlos: RiMa Editora, p. 175-188, 2015.

ZHENMEI, M.; SHAOZHONG, K.; LU, Z.; LING, T.; XIAOLING, S. Analysis of impacts of climate variability and human activity on streamflow for a river basin in arid region of northwest China. Journal of Hydrology, v. 352, n. 3-4, p. 239-249, 2008.

This is an Open Access article distributed under the terms of the Creative Commons Attribution Non-Commercial License which permits unrestricted non-commercial use, distribution, and reproduction in any medium provided the original work is properly cited. 